\title{
The ecology of plant interactions: \\ A giant with feet of clay
}

5 Ciro Cabal $^{1 *}$, Ricardo Martinez-Garcia ${ }^{2}$, Fernando Valladares $^{3,4}$

1- Department of Ecology and Evolutionary Biology, Princeton University, Princeton, NJ 08544, US

2-ICTP-South American Institute for Fundamental Research - Instituto de Física Teórica

10 da UNESP, Rua Dr. Bento Teobaldo Ferraz 271, 01140-070 Sao Paulo SP, Brazil.

3- LINC-Global, Department of Biogeography and Global Change, National Museum of Natural Sciences, MNCN, CSIC, 28006 Madrid, Spain

4- Department of Biology, Geology, Physics and Inorganic Chemistry, Rey Juan Carlos University, Móstoles, 28933 Madrid, Spain

15

*cabal@princeton.edu 


\begin{abstract}
Community ecologists value the phenomenological observation of plant biotic interactions because they provide assumptions to make predictions of other ecosystem features, such as species diversity, community structure, or plant atmospheric carbon uptake. However, a rising number of scientists claim for the need of a mechanistic understanding of plant interactions, due to the limitations that a phenomenological approach raises both in empirical and modeling studies. Scattered studies take a mechanistic approach to plant interactions, but we still lack an integrated theoretical framework to start approaching holistically. In this Review and Synthesis, we present a comprehensive foundation for the study of the mechanisms underpinning the net interaction between two plants. First, we recapitulate the elementary units of plant interactions, i.e. all the known biophysical processes affected by the presence of an influencing plant and the possible phenotypic responses of influenced plants to these processes. Following, we discuss how a net interaction between two plants may emerge from the simultaneous effect of these elementary units. We then touch upon the spatial and temporal variability of this net interaction, and scrutinize how that variability may be linked to the underlying biophysical processes. We conclude by arguing how these processes can be integrated in a mechanistic framework for plant interactions, and why it must necessarily focus on the individual scale, incorporate the spatial structure of the community, and explicitly account for environmental factors.
\end{abstract}

Keywords: Biotic interactions, Community ecology, Ecological modelling, Ecological patterns and processes, Spatial ecology, Theoretical ecology 


\section{Introduction}

Biotic interactions are fundamental ecological predictors, and its theoretical treatment produces predictions of major ecological features of plant communities. For instance, plant-animal interactions shape plant communities in several ways: herbivory promotes plant biodiversity (Janzen 1970) and limits plant productivity (Polis 1999), and pollination prevents plant species extinction (Goulson et al. 2015). Biotic interactions, however, are more intense between phylogenetically related taxa (Violle et al. 2011) and the interactions among plants themselves (hereafter plant interactions) are of special

relevance, as plants intensively, ubiquitously compete with each other for the same resources. Based on assumptions about the nature of net interactions, theoretical ecologists explain and predict ecosystem structure and dynamics, from the landscape to the terrestrial scale. For instance, plant net interactions allow to forecast climate change scenarios (Brooker 2006) and explain the plant community efficacy at up-taking atmospheric carbon thereby buffering atmospheric climate change (Franklin et al. 2016). Plant interactions also shape the diversity and distribution of land plants in the globe (Tirado and Pugnaire 2005, Bulleri et al. 2016) and their persistence under anthropogenic climate change conditions (Valladares et al. 2015). Additionally, spatial models for vegetation dynamics in semiarid drylands predict the existence of sudden, hard-to-revert desertification events (Rietkerk et al. 2002). It is indisputable that all these predictions are transcendental.

Pushed by overarching ecological theories, empiricists have tended to observe and report the net interactions among plants. For instance, an ecological theory of biodiversity maintenance states that more intense intraspecific interference relative to interspecific interference stabilizes species coexistence (Chesson 2000) -species coexistence being axiomatic to species diversity. Under these lenses, many empirical studies compare 
intraspecific with interspecific net interactions in order to explain biodiversity variability across biomes, providing support to theoretical predictions (Lamanna et al. 2017, Adler et al. 2018). A different theory states that facilitation by nurse plants promotes coexistence, expands species' niches, and ultimately leads to higher biodiversity in stressful habitats (Callaway 1995, Bulleri et al. 2016). To validate it, hundreds of empirical studies have reported and quantified positive interactions among plants (Soliveres and Maestre 2014). Similarly, theory predicts that vegetation patchiness could be used as an indicator of imminent desertification transitions in drylands, where local facilitation is a driving process (Kéfi et al. 2007). Following, empiricists became interested in relating vegetation cover and patch size distributions to the provision of ecosystem functionality (Berdugo et al. 2017). These observational studies clearly provide phenomenological support for ecological theory.

While the relevance of these theories and their observational support is beyond argument, a rising number of scientists yearn for a finer mechanistic understanding of the plant interaction processes that lay the foundation for them. On the one hand, theories that rely on assumed net interactions among plants risk misleading the mechanisms behind their predictions. For instance, models for vegetation pattern formation reproduce the same family of patterns regardless of whether net interactions among plants are assumed to be purely competitive (Martínez-García et al. 2013a, 2014) or a combination of facilitation and interference, each of them dominating at different distances from the influencing plant (Rietkerk et al. 2002). Hence, while the vegetation patterns produced by both these models can be observed in drylands around the world (Borgogno et al. 2009a), the actual mechanisms creating these patterns still remain uncertain. On the other hand, observational studies reporting net interaction patterns in nature may not be free from methodological and statistical biases (Rinella et al. 2020). Disentangling biases from the 
data used in these studies is tricky without more information about the mechanisms underpinning plant interactions, and a rising number of empiricists and statisticians claim for studies that tackle that type of knowledge (Detto et al. 2019).

95 Shedding light on the mechanisms that underpin the assumed or observed net interactions is an essential pending task for plant interaction ecologists. Here, we present a summarizing revision of the literature on the mechanisms underpinning plant interactions, hoping to establish a novel conceptual framework for its study. Indeed, pairwise interactions between organisms of a biological community can be decomposed in various nested elements: Each pairwise interaction is composed of two net interactions going in opposite directions -from one individual to another- which, in turn, integrate several trophic and non-trophic interaction forces (Callaway and Walker 1997) (Figure 1). What is mechanistic and what is, by opposition, phenomenological will depend to a large extent on one's standing point (what is mechanistic to one can be seen as phenomenological to other interested in a deeper level of detail). We consider these interaction forces as the basic mechanisms explaining plant interactions. On the other hand, observing or assuming the overall biological effect of a neighbor on a focal individual (the net interaction) without any further consideration will be considered a phenomenological approach. In this article, we first recapitualte the elemental biophysical processes by 110 which plants can interact with each other. Second, we address plant phenotypical responses to these interaction forces from the necessary but not widespread game theory perspective. Third, we analyze how interaction forces and plant strategies may integrate into a directional net interaction, i.e. the overall biological effect of one plant on another. Fourth, we tackle the effects that the distance between the pair of interacting plants has on the interaction forces and the net interaction. Fifth, we discuss how net interactions may change in space and time, and how that relates to the elemental mechanisms of plant 
interactions. Sixth, based on all of the above, we propose the development of plant interaction models (PIMs): models based in biophysical and physiological processes in which plant net interactions are not included but rather emerge from a precise description of their underlying interaction forces. We argue that PIMs need to explicitly account for the discrete plant individuals, the spatial configuration of the community, and the environmental variables that drive the various biophysical processes. Contrarily, an overarching focus on the species identity of the interacting individuals should be discouraged in mechanistic plant interaction studies. Overall, we identify the strengths and weaknesses of this broad area of plant ecology, concluding that we have a lengthy path ahead in order to properly understand plant biotic interactions mechanistically.

Unfortunately, lexical arbitrariness leads to confusion in the biotic interaction literature. An established definition of the existing terms referring to biotic interaction levels and mechanisms would make literature more clear and comprehensible (Trinder et al. 2013). A paradigmatic example illustrating this confusion is the word competition, which is used interchangeably to refer to different things. In community-level biotic interaction charts, competition is used to refer to the negative pairwise interaction (-/-), as opposed to, for instance, mutualism (+/+) (e.g. in Godsoe et al. 2017). In some fields, such as plant positive interactions research, it is common to use competition to refer to a negative net interaction, as opposed to facilitation (Filazzola and Lortie 2014). Finally, in an ecophysiology context, competition is the fight among individuals for a specific resource (Grime 1973), regardless of whether the net interactive effect is positive or negative, hence being an interaction force. This last definition is also backed by the Merriam Webster dictionary in which competition is defined as "active demand by two or more organisms or kinds of organisms for some environmental resource in short supply”. This problem similarly affects other related terms (West et al. 2007). To avoid confusion 
within this text, and hopefully to contribute a more clear use of the words across subdisciplines, we propose a glossary of biotic interaction terms in Table 1, and consistently use italics thorough the text to highlight the words that are defined on it.

\section{1- The biophysical processes underpinning plant interactions}

A first, necessary step to properly discuss how a net interaction can be mechanistically explained is to become aware of and bear in mind the several, somewhat independent biophysical processes underneath it. In the context of plant interactions, biophysical processes can be classified in primary processes (the direct effects of the influencing plants in their immediate surrounding), intermediary processes (any biophysical process mediating between the above and the following), and interaction forces (the biophysical changes resulting from the influencing plant that directly affect the influenced plant, i.e. the proximal cause of the interaction).

155 The main primary processes are the effects of plant canopy casting shade (Valladares et al. 2016), baffling wind (Leonard and Croft 2006), intercepting rainfall (Muzylo et al. 2009), and transpirating water (Flerchinger et al. 2015); the effects of both plant canopies and root crowns producing litter (Xiong and Nilsson 1999); and the effects of root crown absorbing soil water (Lambers et al. 2008a), exuding plant water (Prieto et al. 2012), absorbing mineral nutrients (Lambers et al. 2008b), altering soil physical structure (Angers and Caron 1998), and exuding metabolites (Bertin et al. 2003). These primary processes ultimately affect, sometimes antagonistically, several interaction forces, as it is, for example, the case of shade in hot, semi-arid habitats (Figure 2).

A review of the plant interaction literature allowed us to identify twenty one types of interactions forces (classified in four groups: competition, climate amelioration, soil 
amelioration and other cases) that should be considered in order to understand mechanistically each single net interaction (Figure 3). The full literature review explaining each of these mechanisms of interaction, including references to studies addressing them, can be seen as an electronic supplementary material attached to this Review and Synthesis (SM: A review of plant interaction mechanisms).

\section{2- The phenotypic response of plants to interactions}

From a mechanistic perspective, recognizing the interaction forces by which an influencing plant affects an influenced partner is as important as it is understanding how the influenced plant phenotypically responds to them. After reviewing the interaction forces in the previous section, we now discuss observed plant phenotypical responses. Indeed, plants can sense their surrounding habitat (McNickle et al. 2009) and show plastic phenotypical responses to the presence of neighbors (Abakumova et al. 2016, Turcotte and Levine 2016). Game theory, originally developed to study the interaction among rational decision-makers, became an important framework to investigate evolutionary questions towards the end of the XX century (Maynard Smith 1982). More recently, it has become a very successful framework to study plant phenotypical responses to biotic interactions in an evolutionary context (Mcnickle and Dybzinski 2013). In times of classic optimality (Parker and Maynard Smith 1990), game theory revolutionized the field of evolutionary ecology, because it demonstrated that "non-optimal" traits may evolve when the payoffs (that is, the difference between the reproductive benefits of a given strategy and the costs of adopting it) of a resource-allocation strategy are evaluated in the presence of interacting individuals. We distinguish henceforth an individual optimal (the strategy maximizing the net reward for an individual regardless of what other individuals in the 
190 population do), from a collective optimal (the strategy maximizing the overall net reward for a whole population of individuals), and from an evolutionary stable strategy (ESS, a strategy that maximizes the net reward for an individual that selfishly interacts with other individuals of the population, i.e. a strategy that cannot be invaded by any other strategy adopted other individuals engaged in the game). While game theory provides methods to solve for collective optimization (Pareto-optimality, see Pulliam et al. 1982), it is often assumed that individual responses to biotic interaction forces follow ESS. We hope that the following two examples -the arms race of plants in competition for light and the tragedy of the commons in competition for soil resources- will clarify, for unfamiliar readers, the meaning of this important game-theoretical concepts and models.

200 Game theory predicts that plants competing for light should engage in an arms race (Falster and Westoby 2003, Dybzinski et al. 2011). In ecology, an arms race can be defined as a reciprocal, unstable runaway escalation between two interacting parts (Dawkins and Krebs 1979). To understand the arms race in competition for light, let's picture a plant as a photosynthetic crown placed on top of a woody trunk. The crown area of plant will determine its potential to intercept light and therefore, its yield. The individual optimal strategy for plants is to invest all their resources into growing a flat photosynthetic crown at the ground level (Figure 4a). By increasing the sunlight interception, the plant will multiply the amount of foraged resource at each time step. However, in interaction with neighbor plants, competition for light is asymmetric (taller 210 individuals get most of the resource and shaded individuals almost none). Therefore, a plant may benefit from investing some resources into growing its trunk, surpassing the height of its neighbors, and thereafter growing its crown. Nevertheless, if neighbors show this same behavior, all plants in the community end up investing most of their resources into conflict without getting any clear benefit from it (Figure 4b). Indeed, trees invest 
215 about $80 \%$ of their biomass in growing robust columns of wood on top of which they place their leaf canopy (Poorter et al. 2015). If trees cooperated, they would have the exact same crown area exposed to sunlight, but at the level of the ground (Figure 4c), thereby intercepting the same light at a much lower cost. In that case, all the energy gathered from sunlight could be invested in reproduction.

When it comes to competition for soil resources, game theory predicts that plants engage in a tragedy of the commons (Gersani et al. 2001, Zea-Cabrera et al. 2006). That is, the collective action of a group of individuals acting independently and according to their own self-interest leads to the depletion of the shared resource (Hardin 1968). To understand this counterintuitive concept of a tragedy of the commons in competition for soil resources, let's now imagine that a plant has access to a patch of soil with 100 units of resource. In this patch, the plant can grow roots at a cost of 8.66 units of resource per root, and each new root increases total foraging by half the amount of remaining resource in the patch, i.e. the first root would uptake 50 units, the second root would increase the total uptake by 25 units, the third root by 12.5 , and so on. For a single plant, this increase in uptake is the marginal gain that each consecutive root has for the plant. Importantly, this means that the allocation of new roots reduces the resource uptake per root of preexisting roots (hereafter, new roots "steal" resources from pre-existing roots). For example, in the two-root scenario the average uptake per root is $75 / 2=37.5$, therefore the second root has stolen from the first one $37.5-25=12.5$ units of resource. In this hypothetical scenario, the plant will not grow more than three roots, because the marginal benefit of a fourth root is lower than its allocation cost $(6.25<8.66)$ (Figure $4 \mathbf{d})$. Next, consider that a second plant accesses the same patch inhabited by the three-rooted plant. The marginal benefit of the new plant allocating a first root is 23.43 (which coincides with the average uptake per root $[50+25+12.5+6.25] / 4)$. Notice that the marginal benefit 
240 of the second plant allocating its first root is different from the first plant allocating a fourth root (6.25). This is due to the fact that, because new roots reduce resource uptake of pre-existing roots, the new plant steals from its neighbor! The second plant still benefits from allocating a second and a third root in the same patch, and this whole process repeats if a third individual colonizes the patch, then a fourth, and so on (Figure 4e). The more 245 plants colonize the patch, the more roots, and the less efficiently plants forage resources. This exploitative process can continue with a limit set by the point at which the cost of a root equals the average uptake per root (with 11 roots in our example). As plants increasingly deplete the resource in the patch, the net gain goes to zero. This theoretical prediction is supported by some empirical evidence of increased root allocation of plants in response to the presence of neighbors (Maina et al. 2002, O'Brien et al. 2005, but see Semchenko et al. 2007). In our example, the collective optimum (maximization of the net gain) is attained with three roots, regardless of how many plants they belong to (Figure 4f).

In their review, Mcnickle and Dybzinski (2013) address cases, beyond competition for light and competition for soil resources, in which plants may engage in a tragedy of the commons, such as the case of attracting or repelling allies or enemies. As in the examples addressed before, the allocation of resources to plant defenses against enemies must not be seen as an individual optimization of developing defenses. The strategy of the neighbors must be considered too, since neighbors can deflect enemies to the focal plant by investing more in its own defense. Similarly, low plant investment in attracting allies can limit the availability of such allies in the non-attractive local environment, yet too much investment by neighbors can increase competition for them by decreasing the rate at which they visit the focal plant. While necessary to capture the relevant ecological responses of plants to interaction forces, Mcnickle and Dybzinski (2013) conclude that 
265 the game theoretical approach is still not widespread in the plant community ecology literature.

\section{3- Scaling up to the net interaction}

The different interaction forces and the phenotypical responses of plants scale-up leading

to the emergence of net interactions. Our understanding of this integration process is very poor (Filazzola and Lortie 2014). A first step towards linking net interactions to the underpinning mechanisms is to have a clear idea of what a net interaction is. In general, the net interaction is the net effect the neighbor has on the fitness of the focal plant, i.e. the success at passing its genes to the next generation (Hamilton 1964). While simple to state from a theoretical perspective, evaluating the actual fitness of an individual plant is almost impossible empirically. Hence, researchers need to resort to indicators that can be measured in the field, such as the allocation of biomass into reproduction, hereafter fecundity. The fitness-fecundity relation depends on many factors - differences between pollen or ovules (Primack and Hyesoon Kang 1989), seed number to seed size ratio (Geritz et al. 1999), diminishing returns of increased seed sets (Campbell et al. 2017)but fecundity is generally considered a good indicator of fitness. Net interactions are often assessed by comparing a plant's fecundity measures in the presence and (all else equal) in the absence of a neighbor of interest (Figure 5, red arrow). Proxies such as dry biomass or growth rates tend to correlate well with fecundity in plants, and are often used as surrogates (Younginger et al. 2017). Indexes to calculate the net interaction based in this type of observations exist (Armas et al. 2004). A recent study has showed that the direction of the observed net interaction among plants may, however, depend on the fecundity surrogate (dry biomass, seed germination, or plant survival), indicating that 
empirical observations of net interactions must be interpreted with caution (Lozano et al. 2017). From a mechanistic perspective, this is a non-surprising finding as biophysical processes may affect differentially these measures: For instance, (21) attracting allies such as pollinators will increase the focal plant's seed yield but it seems unlikely that it would affect its not somatic plant biomass, (1) competition for light seen as an arms race should increase plant biomass at the expense of reproductive allocation, and (10) increase soil moisture will potentiate plant somatic growth but there is uncertainty on how it should affect reproductive yield. All in all, two main questions need to be addressed in order to dive into the mechanisms underpinning plant net interactions:

First, how can we make a connection between biophysical processes and the observable net interaction? This question remains open, and very few studies have tried to address the complexity of this problem. For instance, Valladares et al. (2016) reviewed how the net interaction results from the integration of several biophysical processes focusing on a primary process: canopy shade. Canopy shade is an interesting example, as it is linked to diverse biophysical processes of different nature (light, water, and thermic stress) that affect antagonistic interaction forces (see Figure 2). Shading is a ubiquitous competitive mechanism that generates plant stress because it limits sunlight energy. However, in hot arid conditions, shade activates positive interaction forces, potentially reducing water stress, heat stress, and even photoinhibition of photosynthesis. This approach (i.e. focusing on a primary process) is particularly interesting for empirical researchers because primary biophysical processes, like shade, can be artificially manipulated in experimental setups keeping all the other variables under control (De Castanho and Prado 2014). A different way to tackle the integrative study of the interaction mechanisms is from a resource-based perspective. For instance, Butterfield et al. (2016) simulated water flows in soils and plants in order to test whether facilitation interactions could emerge, 
and, if so, under which conditions. Of course, water-related interactions forces are not imposed in their model, but they rather emerge from the abiotic and biotic water movements. This alternative approach (focusing on biophysical processes around a specific resource) is advantageous for modeling, as models can simulate the flow of a resource through the ecosystem physical parts. A resource-based theoretical approach requires modeling the fluxes of a given resource in the habitat of the focal plant with and without the interacting neighbor, and the difference in environmental stress between both conditions is a mechanistic explanation to the difference in fitness that the focal plant experiences (Figure 5, water flows and blue arrow).

Second, how do plants respond phenotypically to several interaction forces entangled with each other in highly nonlinear ways (Meron 2015)? Ecologist have long been interested in the study of plant strategies to cope with resource co-limitation. For instance, Bloom et al. (1985) developed the optimal foraging hypothesis, stating that plants will adapt their phenotype so that all essential resources are equally limiting. More recently, and in the frame of evolutionary game theory, McNickle et al. (2016) developed a triple game theory model of allocation of biomass to leaves, stem and roots. They noticed that, while classic-optimality life-history models predict that plants should allocate all their resources into reproduction after reaching a threshold size (Bazzaz et al. 1987), observations from forests show that trees invest less than 10\% to reproduction (Luyssaert et al. 2007). From an original approach that combines the ESS of plants in aboveground and belowground competition, they predicted that plants forage inefficiently, overallocating resources into roots, stems, and leaves, at the expense of their lifetime fecundity. The model, in which allometries emerge naturally from allocation strategies rather than being imposed, was surprisingly successful at predicting the physiognomy of vegetation in the different biomes. For instance, plants with less stem than roots or leaves 
were more abundant in habitats corresponding to shrubland biomes, while plants investing most to stems dominated in wet tropical climates.

\section{4- The effect of the distance between plants on interactions}

The zone of influence of a plant, defined as the space circumscribing all other individuals that interact with the focal plant, is a concept developed in the late sixties (Opie 1968) ecology. The introduction of this concept fostered the development of statistical methods to infer the range and sign of net interactions between plants from spatial point patterns, starting with the Ripley's K index (Ripley 1978). Statistical spatial correlations can be used as a proxy to many ecological processes (McIntire and Fajardo 2009), providing an alternative approach to empirically reporting net interactions from the observation of fitness differences. For instance, clumped vegetation patterns must be observed when there is facilitation (Haase et al. 1996) but over-dispersed patterns emerge under interference when competition is asymmetric (Stoll and Bergius 2005). The field of spatial plant ecology has been extensively developed (for a comprehensive review of spatial correlation techniques see Dray et al. 2012, and of the ecological importance of patterns and scale see Chave 2013). Here, we focus on the scarcer literature studying mechanisms underpinning the change in net interaction with increasing distance between two plants.

Probably, the first interaction force that was explicitly suggested to vary with the distance between two plants is the effect of a plant attracting enemies (herbivores or diseases) to another plant, as stated by the famous Janzen-Connell hypothesis (Janzen 1970, Connell 1971). Generally, all interaction forces in Figure 3 and all biophysical processes 
described in Section 1 must vary in intensity with the distance from an influencing plant. Normally, they may progressively lose strength with increasing distance to the plant center. In a very particular case, two antagonistic interaction forces are spatially complementary: (3) competition for runoff water happens in bare soils at intermediate distances from the plant because plants (10) increase soil moisture under their canopy. Indeed, both interaction forces rely on the same primary process: the ability of the influencing plant to increase infiltration by altering the soil's structure (Figure 6a). This particular case underscored for the first time the possible emergence of scale dependent feedbacks (SDF) in net interactions, meaning that the net interaction may switch sign at different plant-plant distances. Based in these specific two interaction forces, one can expect facilitation when plants are close by, but interference when they are farther away (Bromley et al. 1997). This particular type of SDF is sufficient to give rise to particular spatial patterns in semi-arid open-canopy vegetation, such as vegetated spots or bands (Hillerislambers et al. 2001), as well as to globally bistable systems threatened by catastrophic, irreversible desertification events (Rietkerk et al. 2004). These models of spatial pattern formation have received great attention until today (Rietkerk and van de Koppel 2008, Borgogno et al. 2009b, Zelnik et al. 2013, Martínez-García and López 2018). However, from a mechanistic point of view, they are probably excessively simplistic because they only account for two complementary interaction forces.

All interaction forces must vary with space, and at least to a certain extent, they are spatially independent from each other. To understand the change in net interaction with increasing distance between the plants, which may be either a sign switch or just a strength decay, the scaling-up of interaction forces to net interactions needs to be applied independently at each distance from the influenced plant. Very few studies have done so, but a particular example serves to illustrate this idea. The example is provided by the 
work by Trautz et al. (2017), who studied two independent, antagonistic water-mediated interaction forces: (3) competition for soil water and (6) increase in atmospheric water potential. Competition for soil water had a stronger (negative) effect on water stress for the focal plant within the root crown of the influencing plant. However, by transpiring water that is transported by wind, the influencing plant reduced water stress in its surroundings outside its root crown (Figure 6b). This study has two important implications. First, it shows how interaction forces spatially independent from each other may cause a shift in net interaction with the distance between plants (the former case was based in two dependent interaction forces). Second, it shows that, when investigating different water-related biophysical processes, one could find cases of SDF different from the classic SDF used in spatial pattern formation studies (e.g. interference when the plants are close by and facilitation when they are farther away). However, it still leaves open the question of what net interaction would result from the integration of all the waterrelated biophysical processes (shown in Figure 5).

To end this section, we discuss how individual phenotypic responses to interaction forces change with distance between individuals. Because most game-theoretical models investigating plant behavioral responses are not spatially-explicit, this question remains largely unexplored. There is very little literature addressing this problem, as indeed most game theoretical models of plant ecology are not spatially explicit. However, a recently published theory, based in the exploitative response of plant roots to water dynamics in the soil, predicts that plants over-proliferate roots and thus engage in a tragedy of the commons in response to near neighbors, but under-proliferate roots when neighbors are further apart (Figure 6c) (Cabal et al. 2020). This novel theory reconciles the two seemingly opposing hypotheses in root foraging literature discussed above, root territoriality (which intuitively led to assume under-proliferation) and the tragedy of the 
commons. It also highlights the importance of incorporating spatial processes in plant game-theoretical models.

\section{5- A dynamic view of the net interaction}

The biophysical processes and the plant phenotypic response to interaction forces vary with time and space. This might be due to changes in the distance between the plants, in the functional traits of the interacting plants, and in the environmental conditions (Figure

7). In order to mechanistically explain the net interaction between two given plants in a given location and moment, researchers need to account for the dynamism of these drivers. In the previous section, we reviewed the case of the distance between plants. In the following, we will discuss how spatiotemporal changes in environmental conditions and plant functional traits modify net interactions, and their implications for a mechanistic study of plant interactions.

Firstly, the environment quality is a major driver of changes in net interactions. Grime (1973) reported, for the first time, on more intense competition with increasing environmental quality. Later, facilitation among plants started to interest community ecologists (Hunter and Aarssen 1988), leading to the development of the stress gradient hypothesis (SGH). The SGH states that positive interaction forces may dominate with increasing environmental stress, allowing the emergence of facilitation (Bertness and Shumway 1993). It mostly predicts the prevalence of facilitation or interference in relation to spatial variation in habitat conditions (Maestre et al. 2005), but temporal heterogeneity may also produce switches in the sign of net interaction at the scale of days

435 (Wright et al. 2015), seasons (Breshears et al. 1998, Kikvidze et al. 2006) and even between years (Valladares and Pearcy 2002, del Río et al. 2014). A variation of the SGH 
(the so called hump-shaped SGH) suggests that, while facilitation may emerge under increasing stress in mild environments, the net interaction may switch back to interference under extreme stress conditions (Holmgren and Scheffer 2010). This collapse of facilitation has been reported in water-limited habitats (Maestre et al. 2003), cold climates (Koyama and Tsuyuzaki 2013), and along gradients of grazing intensity (Michalet et al. 2014). Nevertheless, facilitation has been reported in one of the most inhospitable land surfaces on earth: Antarctica (Molina-Montenegro et al. 2013).

From a mechanistic point of view, environmental conditions modify the biophysical processes that underpin plant interactions. While many studies report changes in net interactions across stress conditions, very few studies accurately report the biophysical processes responsible for those changes. We have argued that by modeling the biophysical processes related to a specific resource, we could explain mechanistically the difference in fitness a that plant experiences in the presence of a neighbor (see Figure 5). Indeed, the model we used as an example to illustrate this in Section 3 (Butterfield et al. 2016) incorporates environmental variation. By running their simulation under different environmental conditions, the authors could compare changes in water stress in the presence or absence of a shrubby neighbor in different habitat conditions. They concluded that the effect of a shrub on altering water stress conditions was different under changing precipitation regimes. They found, for instance, that the positive effect of shrubs on superficial soil water decays with a decrease in precipitation, giving support to a humpshaped SGH. Also Anthelme et al. (2012) evaluated empirically the effect of nurse plants along an altitude gradient. They observed interference in low altitudes but facilitation at higher stress conditions. They then measured the interaction forces involved and identified (9) soil nutrient enrichment and (10) increase in soil water as the main drivers. 
The type of data they gathered represents a first step towards the mechanistic understanding of shifts in net interaction across environmental gradients.

Secondly, the functional traits of the two interacting plant are a major driver of changes in net interactions. Global-scale studies relate the intensity and the sign of the net 465 interaction between plants to their functional traits (Kunstler et al. 2016, Fichtner et al. 2017). Plant functional traits have an evident genetic background that is species-specific (Pereira and Des Marais 2020). As a consequence, interaction studies report co-occurring cases of interference and facilitation, where shifts in net interaction depend only on the species identity of the influenced (Choler et al. 2001) or the influencing (Pugnaire et al. 470 2004) individuals. However, functional traits are far from being solely restricted to species identity (Cadotte et al. 2011). They vary with ontogeny, plant size being a paradigmatic example of that change. Some studies have reported shifts in the net interaction with increasing size of the influencing plants (Miriti 2006), of the influenced plant (Soliveres et al. 2010), and when both plants grow together (Schiffers and

475 Tielbörger 2006) within species pairs. Both species identity and the size of the individuals should be considered together as drivers of plant functional traits that affect net interactions (Álvarez-Yépiz et al., 2014). Additionally, modern functional ecology underscores the need to account for the ample environmentally-induced phenotypic plasticity that ultimately has strong effect in plant net interactions (Valladares et al. 2007).

480 From a mechanistic approach, the functional traits of the influencing plant modify the biophysical processes underpinning plant interactions. For instance, shorter plants will have a smaller zone of influence (Casper et al. 2003), plants with higher specific root length may compete for soil resources more efficiently (Erktan et al. 2018), plants with deeper roots can increase superficial soil water trough hydraulic lift (Walter 1971), or 485 plants with higher leaf-area index will produce a more intense shade (Jordan 1969). The 
treatment of functional traits variation needs to be careful, as the plant will respond with plasticity to both the interaction forces from other plants (already tackled in Section 2) and to abiotic factors addressed here. Discerning the phenotypic plasticity of a plant in response to environmental change, and the phenotypic variation produced within a given habitat by the presence of neighboring plants is an arduous task.

Environmental sciences need to provide predictions of major ecologic features in the frame of the current anthropogenic global crisis. Understanding global-scale spatial and temporal vegetation responses to climate change, mediated at least partially by plant interactions, is necessary to provide these answers (Scheiner et al. 2011). Our current understanding of plant ecophysiology presumably provides tools to start approaching a theoretical treatment of this problem, but its complexity, as depicted through this Concepts and Synthesis, is enormous. Some studies have tackled multi-level effects phenomenologically. For instance, Wright et al. (2014) showed how both biotic (ontogeny) and abiotic (circadian cycles and seasons) temporal factors together drive 500 complex, continuous changes in the net interaction between two plants. Bonanomi et al. (2016) provided an example of how both the direct abiotic effect of environmental stress and plasticity in the phenotypic response of influencing plants to that stress drive in combination spatial changes in the net interaction. Metz and Tielbörger (2016) considered the spatiotemporal variation altogether, reporting facilitation only in certain 505 locations and at specific times at which stressful environmental conditions arise. However, we are still far from a mechanistic framework that, based on biophysical processes, would allow us to predict how net interactions vary in time and space with the distance between plants, the functional traits of the plants, and the environmental conditions in which the interaction takes place. 


\section{6- Conceptual approaches to plant interactions}

Plant communities can be studied at various scales, from plant foraging organs, to individuals, to populations, to the whole community (Figure 8a). In this section, after recapitulating the strengths and weaknesses of models that focus on each of them, we discuss the necessity of developing a new approach to plant community ecology in which plant net interactions are not assumed but emerge naturally from a detailed description of their underlying biophysical and physiological processes: the plant interaction models (PIMs). We claim that PIMs need to abandon the current focus on the species identity of interacting individuals and, at least in their initial development, they should move towards an explicit description of discrete plant individuals, the spatial structure of the community, and surrounding environmental factors. The development of this models may open the doors for a new conceptual approach to the mechanistic study of plant interactions, yielding hypothesis that could be empirically tested.

Following the course of history, the first approach to study populations of interacting agents dates back to the logistic equation for intraspecific competition (Verhulst 1845). Later work by Lotka, Volterra, and others extended this model to systems with more than one species and to other ecological interactions, specially prey-predator (Lotka 1920, 1924, Volterra 1926). At least two factors explain the great success of this family of demographic models during the last century. First, they provide good fits to empirical

530 observations. Notably remarkable are the experiments by Gause et al. (1934) to test intraspecific competition in populations of paramecia and the data from the Hudson's Bay Company on fluctuations of lynxes and hares in Canada, that confirmed predictions of prey-predator models (Hewitt 1921). Second, because demographic models focus on the species identity of the interacting agents and are mathematically tractable (Wangersky 1978), they allowed researchers to identify simple rules that allow coexistence between 
antagonistic species (Hardin 1960). The term "species interactions" has, indeed, been widely used to refer to this demographic approach (see Thompson 1999), yet we refrain from its use as it may lead to confusion. Despite being initially well received and generally acknowledged for several decades (Jeltsch et al. 2008), this approach may 540 currently be no longer so popular among plant ecologists (Reiners et al. 2017).

A first, evident limitation of this population-level approach is based on the fact that plants are sessile organisms and thus interact only with their neighbors. The concerns for the poor suitability of these models to plant communities was probably first raised by Fagerström (1988), who highlighted that sessile organisms must only compete with close

545 neighbors, and supported the use of spatially explicit approaches. Interactions in both Verhulst and Lotka-Volterra equations rely on the so-called law of mass action, which assumes that individuals occupy the entire population range uniformly and are equally likely to interact with each other provided that their trajectories intersect by chance (Hutchinson and Waser 2007, O’Dwyer 2020). These assumptions have been shown 550 inaccurate for many motile organisms, which often show non-uniform space occupation patterns (i.e., home-range), long range perception, and complex foraging behaviors (Hein and McKinley 2013, Hein and Martin 2020, Martinez-Garcia et al. 2020). In sessile communities, the interaction is highly dependent on the distance between individuals and population-level models based on the law of mass action are an overlying approach (see

555 section 4). In addition to the limitations caused by model assumptions, plant demographic empirical studies are generally labor intensive, as they require large sample sizes, longterm, long-range data sets, and large arrays of variables (Ehrlén et al. 2016). The analysis of demographic-level data to asses biotic interaction may be prone to strong statistical biases in the detection of negative density-dependences, which questions a large body of 560 literature explaining plant species biodiversity across biomes (Detto et al. 2019). This 
problem is magnified by the fact that most species coexistence studies are observational, making difficult to control for the variability in neighbors and leading to omitted variable biases in estimated effects of neighbors on targeted plants (Rinella et al. 2020).

Besides these concerns, we argue that these population-level models are by itself limited 565 by the strong focus given to the species identity of the interacting individuals. We have reviewed in detail the several biophysical processes that affect plant interactions, and shown that the effect of many of them acting simultaneously may depend significantly on factors that are not related to species identity. One example is the distance between plants, which may be responsible for a switch in the sign of the interactions between any pair of 570 individuals. Another is the ontogeny of a plant, which may have a higher impact on plant functional traits than species identity. As a simple example, a tree seedling has functional traits that resemble more those of herbaceous plants than those of adult individuals of its own species (Niklas et al. 2007), the most obvious one being its overall size. Therefore, the way this seedling interacts with other plants will be more similar to the way 575 herbaceous plants rather than adult trees of its own species do. All in all, the ontogeny or the distance between two plants have mechanistic effects on the net interaction that may eclipse the potential effects of species identity. In summary, this non-spatial demographic approach, also termed well-mixed, is unable to incorporate all the mechanistic complexity underpinning plant interactions, and hence it is necessarily phenomenological.

580 All the abovementioned concerns claim for the need of a better mechanistic consideration of plant-to-plant interactions that, at least, incorporates explicitly the spatial structure of the community. Two alternative modeling approaches developed during the last decades of the $X^{\text {th }}$ century: The individual-based approach (Bella 1971) and the plant-continuum approach (Lefever and Lejeune 1997, Klausmeier 1999). Most individual-based models

585 (IBM) are computer simulations of individuals interacting in a spatial environment 
composed of independent grid cells of the size of the crown of an adult plant. The first vegetation dynamics IBM of this kind is probably jabowa (Botkin et al. 1972), and this approach has received considerable attention since. Various modeling advances have been developed, such as foret (Shugart, and West 1980) which incorporated dependence 590 between the cells in the grid, and sortie (Pacala et al. 1996) which was the first fully spatially-explicit IBM. The other alternative to well-mixed demographic-level models is the plant-continuum approach, based in partial differential equations (PDEs) for the evolution in time and space of the density of vegetation biomass (Holmes et al. 1994). PDE models for studying vegetation dynamics can be classified in two classes: ecohydrological models, which consist of systems of two or more equations to describe the interaction between vegetation and resources, usually water (Klausmeier 1999, Rietkerk et al. 2002), and kernel-based models (Lefever and Lejeune 1997), which use a single equation to describe the evolution of vegetation biomass. From a more biological perspective, ecohydrological models explicitly describe scale-dependent feedbacks between water and vegetation (Figure 6a), whereas kernel-based models follow an even more phenomenological approach and encapsulate every feedback between plants and their environment in the sign of the net interaction among plants. More sophisticated models lying in each of these classes also include interactions between vegetation and other organisms (Gilad et al. 2004, Bonachela et al. 2015, Tarnita et al. 2017), landscape topography (von Hardenberg et al. 2001, Gilad et al. 2007), and different sources of environmental or demographic stochasticity (D’Odorico et al. 2006, Butler and Goldenfeld 2009, Martínez-García et al. 2013b, Eigentler and Sherratt 2020).

In their review, Meron et al. (2019) stand up in pro of the plant-continuum approach, which, due to its higher mathematical tractability has indeed contributed crucially to our qualitative understanding of several ecosystem-level processes in drylands, with special 
emphasis on desertification transitions (Rietkerk et al. 2002, Bonachela et al. 2015, Meron 2018, Fernandez-Oto et al. 2019). Moreover, the authors defend that, unlike IBMs in which the smallest scale is that of the individual, the plant-continuum approach incorporates a higher resolution in spatial processes because it describes continuous biomass densities. As a result, it can capture processes that occur in a small area element, as small as needed. In doing so, however, plant-continuum models lose the track of individual plants and do not permit to quantify population sizes. We will in the following explain why, based in all the facts exposed through this Review \& Synthesis, we consider that the individual-level is the correct biological scale to study mechanistically plant interactions.

First of all, we agree with (Meron et al. 2019) that IBMs are mathematically less tractable than the ordinary differential equations of well-mixed demographic models or the partial differential equations of plant-continuum models. IBMs require, to a large extent, intensive computer simulations, but tools to treat them analytically also exist, e.g., moment closure methods such as the pair approximation (Matsuda et al. 1992, Ellner 2001, Iwasa 2010), and IBMs are suitable to model plant interactions in all the remaining characteristics shown in Table 2. In addition, while Meron et al. (2019) defend that plantcontinuum models can function at finer spatial scales than IBM because they model biomass densities rather than individuals, we do not see a reason to state that spatially explicit IBMs cannot incorporate processes happening at finer spatial scales that the individual scale, especially when they account for an explicit description of environmental conditions. Moreover, existing PDE-based models deliberately simplify many factors to keep mathematical tractability, which makes most of their results independent of the assumed net interactions. For instance, they predict that the shape of 635 the spatial distribution of plants correlates with water availability. Specifically, as 
precipitation declines, prior to completely dying out, vegetation transitions from fully covering the system, to leaving regularly spaced gaps of bare soil, to forming labyrinthic shapes that resemble a tiger bush, to arranging in isolated spots. Worryingly, this sequence of patterns and the way they correlate with precipitation ranges is independent of the net interactions that a specific model assumes (von Hardenberg et al. 2001, Rietkerk et al. 2002, Martínez-García et al. 2013a). Finally, plant-continuum models cannot track population sizes and individual growth properly. Using mortality as an example, individuals die with increasing cumulative probability, i.e. they do not only die due to resource limitations but also with the age of individuals, a feature that plantcontinuum models cannot incorporate. In addition, when an adult individual dies, a large, discrete spatial portion of biomass disappears altogether, whereas plant-continuum models only produce modular progressive decreases of biomass density.

But, probably, the most important strength of the individual-level approach is its potential to incorporate functional trait variation and game theoretical responses to interaction 650 forces. Functional trait ecology is a rising field that underscores the importance of phenotypic plasticity in plant traits rather than taxonomical identity in community ecology processes (McGill et al. 2006). Population-level approaches cannot incorporate this variability within taxa, and plant-continuum models do not incorporate it within the modeled plant mass. Indeed, neither of these approaches have the correct resolution to incorporate phenotypic plasticity, which is inherently individual-level. Only trait-based IBMs can accurately represent the diversity and spatial complexity depicted by plant functional traits (Zakharova et al. 2019). The game theoretical response of plants to interactions is a paradigmatic example of the inevitability of an individual-level resolution in vegetation models. As we have shown with two examples in section 2, individual plants may behave inefficiently when foraging a shared resource according to 
game theoretical ESS (Rankin et al. 2007). In particular, we have discussed in section 4 how a plant allocation to roots may change from over-allocation (tragedy of the commons) when close to neighbors, to under-allocation when farther away. How could phenomena like these be modeled without incorporating explicitly the individual plants in space? Demographic and plant-continuum models are favored by their simplicity and mathematical tractability. However, they are problematically constrained in how much complexity they can account for, and thus cannot describe the highly complex mechanisms that underlie plant interactions.

To solve this problem, we argue that a new approach should be taken to study plant interactions. Such new family of models, which we call plant interaction models (PIM), should focus on the individual and how it interacts with biophysical processes. This shift is mathematically challenging and will require, at least in the first steps, intensive computation. Plant interaction models, however, incorporate advantageous features from the population-level approach, such as the possibility of tracking population sizes, others

675 from the plant-continuum approach, such as high resolution in spatial processes, and unique features, such as accurately accounting for functional traits and the phenotypic plasticity of plants. By integrating all these features in a single theoretical framework, researchers will be able to investigate how their joint effect spontaneously generates a variety of net interactions that ultimately drive the dynamics of plant communities. PIM not only have the potential to model plant interactions mechanistically, but also to produce hypothesis that can be tested empirically. For instance, researchers may be able to better understand plant facilitation, investigating in which conditions these positive interactions emerge and which positive interaction forces may be their principal drivers. For instance, PIMs may produce a better understanding of the nature of scale dependent feedbacks in the wild, shedding light on the direction of the sign switch and the spatial 
changes in interaction forces that drive it. This will ultimately allow researchers to understand how and in which conditions the changes of the net interaction with the distance between the plants is behind vegetation patterns. Another example is given by the possibility to yield testable predictions on the temporal dynamic of the interference/facilitation switches, and how these may affect the species coexistence in mild and stressful habitats.

\section{Conclusions}

Although often assumed to be the net effect of a neighbor on a focal individual, we have 695 shown that plant interactions actually rely on copious biophysical processes and counterintuitive dynamical responses of plants. Concerns have been raised about the problems underlying the use of a phenomenological approach to plant interactions, claiming for the need to develop a mechanistic understanding that backup some relevant predictions on biodiversity patterns, climate change forecasts, or ecosystem dynamics.

700 We propose a new conceptual approach to the study of plant interactions from a mechanistic perspective, integrating the biophysical processes and the evolutionary stable strategies (ESS) of plants in relation to the spatial configuration of the sessile community, the functional traits of the plants, and the environmental conditions. We highlight that an individual-level approach is necessary for a fully comprehensive mechanistic study of plant interactions, which can integrate biophysical processes, short-scale spatial structure, plant phenotypic plasticity, and ESS. The development of individual-based models incorporating biophysical processes and plants' ESS in which net interactions emerge are necessary to advance our mechanistic knowledge of plant interactions. Empirical studies reporting the mechanisms underpinning net interactions among individuals controlling 
710 for (but not focused in) the species identity of the individuals interacting may also significantly enrich our knowledge of this field. Only by incorporating the high complexity of mechanisms underpinning net interactions from an individual-level approach will the plant interaction ecology firmly stand on its own two feet.

715 Acknoledgements: We thank Isaac Kaz Uyehara, Stephen W. Pacala, and Corina E. Tarnita for some great and insightful conversations on many of the topics addressed here, and Liana Fay Wait for her helpful English language edits. Funding: CC acknowledges funding from The May Fellowship in the department of Ecology and Evolutionary Biology, Princeton University. RMG was supported by the Simons Foundation, and Fundação de Amparo à Pesquisa do Estado de São Paulo (FAPESP) through the ICTP-SAIFR grant 2016/01343-7 and Programa Jovens Pesquisadores em Centros Emergentes 2019/24433-0. Author contributions: All authors contributed to the conceptualization. $\mathrm{CC}$ wrote an initial version of the manuscript. All authors reviewed and edited the text previous submission. Conflicts of interest: Authors declare no competing interests.

\section{References}

Abakumova, M. et al. 2016. Plasticity in plant functional traits is shaped by variability in neighbourhood species composition. - New Phytol. 211: 455-463.

Adler, P. B. et al. 2018. Competition and coexistence in plant communities: intraspecific competition is stronger than interspecific competition. - Ecol. Lett. 21: 
$1319-1329$.

Álvarez-Yépiz, J. C. et al. 2014. Ontogenetic shifts in plant-plant interactions in a rare 735 cycad within angiosperm communities. - Oecologia 175: 725-735.

Angers, D. A. and Caron, J. 1998. Plant-induced changes in soil structure: Processes and feedbacks. - Biogeochemistry 42: 55-72.

Anthelme, F. et al. 2012. Unexpected mechanisms sustain the stress gradient hypothesis in a tropical alpine environment. - J. Veg. Sci. 23: 62-72.

Armas, C. et al. 2004. Measuring plant interactions: A new comparative index. Ecology 85: 2682-2686.

Bazzaz, F. A. et al. 1987. Allocating Resources to Reproduction and Defense. Bioscience 37: 58-67.

Bella, I. E. 1971. A New Competition Model for Individual Trees. - For. Sci. 17: 364 372.

Berdugo, M. et al. 2017. Plant spatial patterns identify alternative ecosystem multifunctionality states in global drylands. - Nat. Ecol. Evol. 1: 1-7.

Bertin, C. et al. 2003. The role of root exudates and allelochemicals in the rhizosphere. Plant Soil 256: 67-83.

Bertness, M. D. . and Shumway, S. W. . 1993. Competition and Facilitation in Marsh Plants. - Am. Nat. 142: 718-724.

Bloom, A. J. et al. 1985. Resource Limitation in Plants-An Economic Analogy. - Annu. Rev. Ecol. Syst. 16: 363-392.

Bonachela, J. A. et al. 2015. Termite mounds can increase the robustness of dryland 

ecosystems to climatic change. - Science (80-. ). 347: 651-655.

Bonanomi, G. et al. 2016. Cushion plant morphology controls biogenic capability and facilitation effects of Silene acaulis along an elevation gradient. - Funct. Ecol. 30: $1216-1226$.

Borgogno, F. et al. 2009a. Mathematical models of vegetation pattern formation in 760 ecohydrology. - Rev. Geophys. 47: 1-36.

Borgogno, F. et al. 2009b. Mathematical models of vegetation pattern formation in ecohydrology. - Rev. Geophys. 47: 1-36.

Botkin, D. B. et al. 1972. Some Ecological Consequences of a Computer Model of Forest Growth. 60: 849-872.

Breshears, D. D. et al. 1998. Effects of Woody Plants on Microclimate in a Semiarid Woodland: Soil Temperature and Evaporation in Canopy and Intercanopy Patches. - Int. J. Plant Sci. 159: 1010-1017.

Bromley, J. et al. 1997. The role of surface water redistribution in an area of patterned vegetation in a semi-arid environment, south-west Niger. - J. Hydrol. 198: 1-29.

Brooker, R. W. 2006. Plant-plant interactions and environmental change. - New Phytol. 171: $271-284$.

Bulleri, F. et al. 2016. Facilitation and the niche: Implications for coexistence, range shifts and ecosystem functioning. - Funct. Ecol. 30: 70-78.

Butler, T. and Goldenfeld, N. 2009. Robust ecological pattern formation induced by demographic noise. - Phys. Rev. E 80: 030902.

Butterfield, B. J. et al. 2016. Does the stress-gradient hypothesis hold water? 
Disentangling spatial and temporal variation in plant effects on soil moisture in dryland systems. - Funct. Ecol. 30: 10-19.

Cabal, C. et al. 2020. The Exploitative Territoriality of Plant Roots. - Rev. in press.

Cadotte, M. W. et al. 2011. Beyond species: Functional diversity and the maintenance of ecological processes and services. - J. Appl. Ecol. 48: 1079-1087.

Callaway, R. M. 1995. Positive Interactions among Plants. - Bot. Rev. 61: 306-349.

Campbell, D. R. et al. 2017. Is plant fitness proportional to seed set? An experiment and a spatial model. - Am. Nat. 190: 818-827.

Casper, B. B. et al. 2003. DEFINING A PLANT'S BELOWGROUND ZONE OF INFLUENCE\rdoi:10.1890/02-0287. - Ecology 84: 2313-2321.

Chave, J. 2013. The problem of pattern and scale in ecology: What have we learned in 20 years? - Ecol. Lett. 16: 4-16.

Chesson, P. L. 2000. Mechanisms of Maintenance of Species Diversity. - Annu. Rev. Ecol. Syst. 31: 343-366.

Choler, P. et al. 2001. Facilitation and Competition on Gradients in Alpine Plant Communities. - Ecology 82: 3295-3308.

Connell, J. H. 1971. On the role of natural enemies in preventing competitive exclusion in some marine animals and in rain forest trees. - In: Boer, P. J. Den and Gradwell., G. R. (eds), Dynamics of Population. Pudoc, pp. 298-312.

D’Odorico, P. et al. 2006. Vegetation patterns induced by random climate fluctuations. Geophys. Res. Lett. 33: L19404.

Dawkins, R. and Krebs, J. R. 1979. Arms races between and within species. - Proc. R. 
Soc. London - Biol. Sci. 205: 489-511.

800

De Castanho, C. T. and Prado, P. I. 2014. Benefit of shading by nurse plant does not change along a stress gradient in a coastal dune. - PLoS One 9: 1-9.

del Río, M. et al. 2014. Temporal variation of competition and facilitation in mixed species forests in Central Europe. - Plant Biol. 16: 166-176.

Detto, M. et al. 2019. Bias in the detection of negative density dependence in plant communities. - Ecol. Lett. 22: 1923-1939.

Dray, S. et al. 2012. Community ecology in the age of multivariate multiscale spatial analysis. - Ecol. Monogr. 82: 257-275.

Dybzinski, R. et al. 2011. Evolutionarily stable strategy carbon allocation to foliage, wood, and fine roots in trees competing for light and nitrogen: An analytically tractable, individual-based model and quantitative comparisons to data.

Ehrlén, J. et al. 2016. Advancing environmentally explicit structured population models of plants. - J. Ecol. 104: 292-305.

Eigentler, L. and Sherratt, J. A. 2020. Effects of precipitation intermittency on vegetation patterns in semi-arid landscapes. - Phys. D Nonlinear Phenom. 405:

815 132396.

Ellner, S. P. 2001. Pair approximation for lattice models with multiple interaction scales. - J. Theor. Biol. 210: 435-47.

Erktan, A. et al. 2018. Frontiers in root ecology: recent advances and future challenges. - Plant Soil 424: 1-9.

Fagerström, T. 1988. Lotteries in communities of sessile organisms. - Trends Ecol. 
Evol. 3: 303-306.

Falster, D. S. and Westoby, M. 2003. Plant height and evolutionary games. - Trends Ecol. Evol. 18: 337-342.

Fernandez-Oto, C. et al. 2019. Front Instabilities Can Reverse Desertification. - Phys. Rev. Lett. 122: 048101.

Fichtner, A. et al. 2017. From competition to facilitation: how tree species respond to neighbourhood diversity. - Ecol. Lett. 20: 892-900.

Filazzola, A. and Lortie, C. J. 2014. A systematic review and conceptual framework for the mechanistic pathways of nurse plants. - Glob. Ecol. Biogeogr. 23: 1335-1345.

830 Flerchinger, G. N. et al. 2015. Modeling temperature and humidity profiles within forest canopies. - Agric. For. Meteorol. 213: 251-262.

Franklin, J. et al. 2016. Global change and terrestrial plant community dynamics. - Proc. Natl. Acad. Sci. U. S. A. 113: 3725-3734.

Gause, G. F. et al. 1934. The Influence of Biologically Conditioned Media on the Growth of a Mixed Population of Paramecium caudatum and P. aureliax. - J. Anim. Ecol. 3: 222-230.

Geritz, S. A. H. et al. 1999. Evolutionary dynamics of seed size and seedling competitive ability. - Theor. Popul. Biol. 55: 324-343.

Gersani, M. et al. 2001. Tragedy of the Commons as a Result of Root Competition. - J. Ecol. 89: 660-669.

Gilad, E. et al. 2004. Ecosystem Engineers: From Pattern Formation to Habitat Creation. - Phys. Rev. Lett. 93: 098105. 
Gilad, E. et al. 2007. A mathematical model of plants as ecosystem engineers. - J. Theor. Biol. 244: 680-691.

845 Godsoe, W. et al. 2017. Interspecific interactions and range limits: contrasts among interaction types. - Theor. Ecol. 10: 167-179.

Goulson, D. et al. 2015. Bee declines driven by combined Stress from parasites, pesticides, and lack of flowers. - Science (80-. ). in press.

Grime, J. P. 1973. Competitive exclusion in herbaceous vegetation. - Nature 242: 344347.

Haase, P. et al. 1996. Spatial patterns in a two-tiered semi-arid shrubland in southeastern Spain. - J. Veg. Sci. 7: 527-534.

Hamilton, W. D. 1964. The genetical evolution of social behaviour. I. - J. Theor. Biol. 7: $1-16$.

Hardin, G. 1960. The competitive exclusion principle. - Science (80-. ). 131: 12921297.

Hardin, G. 1968. The Tragedy of Commons. - Science (80-. ). 162: 1243-1248.

Harper, J. L. 1961. Approaches to the study of plant competition. - Symp. Soc. Exp. Biol. 15: 1-39.

860 Hein, A. M. and McKinley, S. A. 2013. Sensory Information and Encounter Rates of Interacting Species. - PLoS Comput. Biol. in press.

Hein, A. M. and Martin, B. T. 2020. Information limitation and the dynamics of coupled ecological systems. - Nat. Ecol. Evol. 4: 82-90.

Hewitt, C. G. 1921. The periodic fluctuations of our fur-bearing animals. - In: The 

conservation of the wild life of Canada. Charles Scribner's Sons, pp. 213-234.

Hillerislambers, R. et al. 2001. Vegetation Pattern Formation in Semi-Arid Grazing Systems. - Ecology 82: 50-61.

Holmes, E. . E. . et al. 1994. Partial Differential Equations in Ecology : Spatial Interactions and Population Dynamics. - Ecology 75: 17-29.

Holmgren, M. and Scheffer, M. 2010. Strong facilitation in mild environments: The stress gradient hypothesis revisited. - J. Ecol. 98: 1269-1275.

Hunter, A. F. and Aarssen, L. W. 1988. Plants helping plants. - Bioscience 38: 34-40.

Hutchinson, J. M. C. and Waser, P. M. 2007. Use, misuse and extensions of " ideal gas " models of animal encounter. - Biol. Rev. 82: 335-359.

875 Iwasa, Y. 2010. Lattice Models and Pair Approximation in Ecology. - In: Dieckmann, U. et al. (eds), The Geometry of Ecological Interactions. Cambridge University Press, pp. 227-251.

Janzen, D. H. 1970. Herbivores and the Number of Tree Species in Tropical Forests. Am. Nat. 104: 501-528.

Jeltsch, F. et al. 2008. The state of plant population modelling in light of environmental change. - Perspect. Plant Ecol. Evol. Syst. 9: 171-189.

Jordan, C. F. 1969. Derivation of Leaf-Area Index from Quality of Light on the Forest Floor. - Ecology 50: 663-666.

Kéfi, S. et al. 2007. Spatial vegetation patterns and imminent desertification in Mediterranean arid ecosystems. - Nature 449: 213-217.

Kikvidze, Z. et al. 2006. Seasonal shifts in competition and facilitation in subalpine 
plant communities of the central Caucasus. - J. Veg. Sci. 17: 77-82.

Klausmeier, C. A. 1999. Regular and Irregular Patterns in Semiarid Vegetation. Science (80-. ). 284: 1826-1828.

890

Koyama, A. and Tsuyuzaki, S. 2013. Facilitation by tussock-forming species on seedling establishment collapses in an extreme drought year in a post-mined Sphagnum peatland. - J. Veg. Sci. 24: 473-483.

Kunstler, G. et al. 2016. Plant functional traits have globally consistent effects on competition. - Nature 529: 204-207.

895

Lamanna, J. A. et al. 2017. Plant diversity increases with the strength of negative density dependence at the global scale. - Science (80-. ). 356: 1389-1392.

Lambers, H. et al. 2008a. Plant water relations. - In: Lambers, H. et al. (eds), Plant Physiological Ecology. Second. Springer, pp. 163-223.

Lambers, H. et al. 2008b. Mineral nutrition. - In: Lambers, H. et al. (eds), Plant Physiological Ecology. Second. Springer, pp. 255-320.

Lefever, R. and Lejeune, O. 1997. On the origin of tiger bush. - Bull. Math. Biol. 59: $263-294$.

Leonard, L. A. and Croft, A. L. 2006. The effect of standing biomass on flow velocity and turbulence in Spartina alterniflora canopies. - Estuar. Coast. Shelf Sci. 69: $325-336$.

Lotka, A. J. 1920. Analytical Note on Certain Rhythmic Relations in Organic Systems. Proc. Natl. Acad. Sci. USA 6: 410-415.

Lotka, A. J. 1924. Elements of physical biology. - Williams and Wilkins. 
Lozano, Y. M. et al. 2017. Disentangling above- and below-ground facilitation drivers in arid environments: the role of soil microorganisms, soil properties and microhabitat. - New Phytol. 216: 1236-1246.

Luyssaert, S. et al. 2007. CO2 balance of boreal, temperate, and tropical forests derived from a global database. - Glob. Chang. Biol. 13: 2509- 2537.

Maestre, F. T. et al. 2003. Positive, negative, and net effects in grass-shrub interactions in Mediterranean semiarid grasslands. - Ecology 84: 3186-3197.

Maestre, F. T. et al. 2005. Is the change of plant-plant interactions with abiotic stress predictable? A meta-analysis of field results in arid environments. - J. Ecol. 93: $748-757$.

Maina, G. G. et al. 2002. Intra-Plant versus Inter-Plant Root Competition in Beans : Avoidance, Resource Matching or Tragedy of the Commons. - Plant Ecol. 160: $235-247$.

Martinez-Garcia, R. et al. 2020. How range residency and long-range perception change encounter rates. - J. Theor. Biol. 498: 110267.

Martínez-García, R. and López, C. 2018. From scale-dependent feedbacks to long-range competition alone: a short review on pattern-forming mechanisms in arid ecosystems. - arXiv: 1801.01399.

Martínez-García, R. et al. 2013a. Vegetation pattern formation in semiarid systems without facilitative mechanisms. - Geophys. Res. Lett. 40: 6143-6147.

Martínez-García, R. et al. 2013b. Spatial patterns in mesic savannas: The local facilitation limit and the role of demographic stochasticity. - J. Theor. Biol. 333: $156-165$. 
Martínez-García, R. et al. 2014. Minimal mechanisms for vegetation patterns in semiarid regions. - Philos. Trans. R. Soc. A 372: 20140068.

Matsuda, H. et al. 1992. Statistical Mechanics of Population: The Lattice Lotka-Volterra Model. - Prog. Theor. Phys. 88: 1035-1049.

Maynard Smith, J. 1982. Evolution and the Theory of Games. - Cambridge University Press.

McGill, B. J. et al. 2006. Rebuilding community ecology from functional traits. - Trends Ecol. Evol. 21: 178-185.

McIntire, E. J. B. and Fajardo, A. 2009. Beyond description: The active and effective way to infer processes from spatial patterns. - Ecology 90: 46-56.

Mcnickle, G. G. and Dybzinski, R. 2013. Game theory and plant ecology. - Ecol. Lett. 16: $545-555$.

McNickle, G. G. et al. 2009. Focusing the metaphor: plant root foraging behaviour. Trends Ecol. Evol. 24: 419-426.

McNickle, G. G. et al. 2016. The world's biomes and primary production as a triple tragedy of the commons foraging game played among plants. - Proc. R. Soc. B Biol. Sci. 283: 1-9.

Meron, E. 2015. Nonlinear Physics of Ecosystems. - CRC Press.

Meron, E. 2018. From Patterns to Function in Living Systems: Dryland Ecosystems as a Case Study. - Annu. Rev. Condens. Matter Phys 9: 79-103.

Meron, E. et al. 2019. Continuum Modeling of Discrete Plant Communities: Why Does It Work and Why Is It Advantageous? - Mathematics 7: 987. 
Metz, J. and Tielbörger, K. 2016. Spatial and temporal aridity gradients provide poor proxies for plant-plant interactions under climate change: A large-scale experiment. - Funct. Ecol. 30: 20-29.

Michalet, R. et al. 2014. Two alternatives to the stress-gradient hypothesis at the edge of life: The collapse of facilitation and the switch from facilitation to competition. - J. Veg. Sci. 25: 609-613.

Miriti, M. N. 2006. Ontogenetic shift from facilitation to competition in a desert shrub. J. Ecol. 94: 973-979.

Molina-Montenegro, M. A. et al. 2013. Positive interactions between the lichen Usnea antarctica (Parmeliaceae) and the native flora in Maritime Antarctica. - J. Veg. Sci. 24: 463-472.

Muzylo, A. et al. 2009. A review of rainfall interception modelling. - J. Hydrol. 370: 191-206.

Niklas, K. J. et al. 2007. "Diminishing returns" in the scaling of functional leaf traits across and within species groups. - Proc. Natl. Acad. Sci. U. S. A. 104: 8891-8896.

O’Brien, E. E. et al. 2005. Root proliferation and seed yield in response to spatial heterogeneity of below-ground competition. - New Phytol. 168: 401-412.

O’Dwyer, J. P. 2020. Beyond an ecological ideal gas law. - Nat. Ecol. Evol. 4: 14-15.

Opie, J. 1968. Predictability of Individual Tree Growth Using Various Definitions of Competing Basal Area. - For. Sci. 14: 314-323.

Pacala, S. W. et al. 1996. Forest Models Defined by Field Measurements : Estimation, Error Analysis and Dynamics. - Ecol. Monogr. 66: 1-43. 
Parker, G. A. and Maynard Smith, J. 1990. Optimality theory in evolutionary biology. Nature 348: 27-33.

Pereira, C. G. and Des Marais, D. L. 2020. The genetic basis of plant functional traits and the evolution of plant-environment interactions. - Int. J. Plant Sci. 181: 56-74.

Polis, G. A. 1999. Why Are Parts of the World Green? Multiple Factors Control Productivity and the Distribution of Biomass Author. - Oikos 86: 3-15.

Poorter, H. et al. 2015. How does biomass distribution change with size and differ among species? An analysis for 1200 plant species from five continents. - New Phytol. 208: 736-749.

985

Prieto, I. et al. 2012. Water release through plant roots: New insights into its consequences at the plant and ecosystem level. - New Phytol. 193: 830-841.

Primack, R. B. and Hyesoon Kang 1989. Measuring fitness and natural selection in wild plant populations. - Annu. Rev. Ecol. Syst. Vol. 20 20: 367-396.

Pugnaire, F. I. et al. 2004. Soil as a mediator in plant-plant interactions in a semi-arid community. - J. Veg. Sci. 15: 85-92.

Pulliam, H. R. et al. 1982. The scanning behavior of juncos: A game-theoretical approach. - J. Theor. Biol. 95: 89-103.

Rankin, D. J. et al. 2007. The tragedy of the commons in evolutionary biology. - Trends Ecol. Evol. 22: 643-651.

Reiners, W. A. et al. 2017. 100 Years of Ecology: What Are Our Concepts and Are They Useful? - Ecol. Monogr. 87: 260-277.

Rietkerk, M. and van de Koppel, J. 2008. Regular pattern formation in real ecosystems. 
- Trends Ecol. Evol. in press.

Rietkerk et al. 2002. Self-Organization of Vegetation in Arid Ecosystems. - Am. Nat.

1000 160: 524 .

Rietkerk, M. et al. 2004. Self-organized patchiness and catastrophic shifts in ecosystems. - Science (80-. ). in press.

Rinella, M. J. et al. 2020. Omitted variable bias in studies of plant interactions. Ecology 0: 1-7.

1005 Ripley, B. D. 1978. Spectral Analysis and the Analysis of Pattern in Plant Communities. - J. Ecol. 66: 965-981.

Scheiner, S. M. et al. 2011. The underpinnings of the relationship of species richness with space and time. - Ecol. Monogr. 81: 195-213.

Schiffers, K. and Tielbörger, K. 2006. Ontogenetic shifts in interactions among annual 1010 plants. - J. Ecol. 94: 336-341.

Semchenko, M. et al. 2007. Challenging the tragedy of the commons in root competition: Confounding effects of neighbour presence and substrate volume. - J. Ecol. 95: 252-260.

Shugart, H. H. and West, D. C. 1980. Forest Succession Models. - Bioscience 30: 308313.

Shugart, H. H. et al. 2018. Gap models and their individual-based relatives in the assessment of the consequences of global change. - Environ. Res. Lett. in press.

Soliveres, S. and Maestre, F. T. 2014. Plant-plant interactions, environmental gradients and plant diversity: A global synthesis of community-level studies. - Perspect. 

Plant Ecol. Evol. Syst. 16: 154-163.

Soliveres, S. et al. 2010. Spatio-temporal heterogeneity in abiotic factors modulate multiple ontogenetic shifts between competition and facilitation. - Perspect. Plant Ecol. Evol. Syst. 12: 227-234.

Stoll, P. and Bergius, E. 2005. Pattern and process: Competition causes regular spacing 1025 of individuals within plant populations. - J. Ecol. 93: 395-403.

Tarnita, C. E. et al. 2017. A theoretical foundation for multi-scale regular vegetation patterns. - Nature 541: 398-401.

Thompson, J. N. 1999. The evolution of species interactions. - Science (80-. ). 284: $2116-2118$

Tirado, R. and Pugnaire, F. I. 2005. Community structure and positive interactions in constraining environments. - Oikos 11: 437-444.

Trautz, A. C. et al. 2017. Role of co-occurring competition and facilitation in plant spacing hydrodynamics in water-limited environments. - Proc. Natl. Acad. Sci. 114: 9379-9384.

Trinder, C. J. et al. 2013. Plant ecology's guilty little secret: Understanding the dynamics of plant competition. - Funct. Ecol. 27: 918-929.

Turcotte, M. M. and Levine, J. M. 2016. Phenotypic Plasticity and Species Coexistence. - Trends Ecol. Evol. 31: 803-813.

Valladares, F. and Pearcy, R. W. 2002. Drought can be more critical in the shade than in the sun: A field study of carbon gain and photo-inhibition in a Californian shrub during a dry El Niño year. - Plant, Cell Environ. 25: 749-759. 
Valladares, F. et al. 2007. Ecological limits to plant phenotypic plasticity. - New Phytol. 176: 749-763.

Valladares, F. et al. 2015. Species coexistence in a changing world. - Front. Plant Sci. 6: $1-16$.

Valladares, F. et al. 2016. Shedding light on shade: ecological perspectives of understorey plant life. - Plant Ecol. Divers. 9: 237-251.

Verhulst, P.-F. 1845. Recherches mathématiques sur la loi d'accroissement de la population. - Mémoires l'Académie R. des Sci. des Lettres des B.-art. Belgique 18: $1-42$.

Violle, C. et al. 2011. Phylogenetic limiting similarity and competitive exclusion. Ecol. Lett. 14: 782-787.

Volterra, V. 1926. Variazioni e fluttuazioni del numero d'individui in specie animali conviventi. - Mem. della R. Accad. dei Lincei in press.

von Hardenberg, J. et al. 2001. Diversity of Vegetation Patterns and Desertification. Phys. Rev. Lett. 87: 198101.

Walter, H. 1971. Introdution. - In: Burnett, J. H. (ed), Ecology of Tropical and Subtropical Vegetation. Oliver \& Boyd, pp. 1-70.

Wangersky, P. J. 1978. Lotka-Volterra Population Models. - Annu. Rev. Ecol. Syst. 9: 189-218.

West, S. A. et al. 2007. Social semantics: Altruism, cooperation, mutualism, strong reciprocity and group selection. - J. Evol. Biol. 20: 415-432.

Wright, A. et al. 2014. Living close to your neighbors: The importance of both 
competition and facilitation in plant communities. - Ecology 95: 2213-2223.

1065 Wright, A. et al. 2015. Daily environmental conditions determine the competitionfacilitation balance for plant water status. - J. Ecol. 103: 648-656.

Xiong, S. and Nilsson, C. 1999. The effects of plant litter on vegetation: A metaanalysis. - J. Ecol. 87: 984-994.

Younginger, B. S. et al. 2017. Is Biomass a Reliable Estimate of Plant Fitness? - Appl. Plant Sci. 5: 1-8.

Zakharova, L. et al. 2019. Trait-based modelling in ecology: A review of two decades of research. - Ecol. Modell. 407: 108703.

Zea-Cabrera, E. et al. 2006. Tragedy of the commons in plant water use. - Water Resour. Res. 42: 1-12.

1075 Zelnik, Y. R. et al. 2013. Regime shifts in models of dryland vegetation. - Philos. Trans. R. Soc. A Math. Phys. Eng. Sci. in press. 


\section{Tables}

Table 1: Glossary

\begin{tabular}{ll}
\hline $\begin{array}{l}\text { Biophysical } \\
\text { process }\end{array}$ & $\begin{array}{l}\text { A local modification of the physical (or chemical) environment that } \\
\text { is a direct or indirect result of the presence of a plant. }\end{array}$ \\
\hline $\begin{array}{l}\text { Primary } \\
\text { (biophysical) }\end{array}$ & $\begin{array}{l}\text { A biophysical process by which a plant directly modify its direct } \\
\text { physical surroundings. }\end{array}$ \\
process & A
\end{tabular}

Interaction force

A biophysical process by which a plant affects the environment of a neighboring plant in a way that has an effect on its fitness.

Competition plants compete for each quantum of light, molecule of water, or ion nutrient.

Net interaction

The net outcome of all the interaction forces, giving the net biological effect of a plant on the fitness of a neighboring plant.

\begin{tabular}{ll} 
Facilitation & $\begin{array}{l}\text { (sensu Callaway, 1995) Positive directional net } \\
\text { interaction. }\end{array}$ \\
\hline Interference & $\begin{array}{l}\text { (sensu Harper, 1961) Negative directional net } \\
\text { interaction. }\end{array}$
\end{tabular}

\begin{tabular}{ll}
\hline $\begin{array}{l}\text { Pairwise } \\
\text { interaction }\end{array}$ & The complete (bidirectional) biotic interaction between two plants. \\
\hline & $\begin{array}{l}\text { Family of models that focus on detailed description of the } \\
\text { biophysical processes and plant phenotypic responses letting the net }\end{array}$ \\
Plant Interaction & $\begin{array}{l}\text { interaction emerge. As we argue they must be individual-based, } \\
\text { incorporate the spatial structure of the community, and explicitly } \\
\text { account for environmental factors. }\end{array}$
\end{tabular}


Table 2: The three classic modeling approaches to plant biotic interactions (from different biological scales): classic demographic models (population), individual-based models (individual), plant-continuum models (foraging organs). $\times$ cannot incorporate, can poorly incorporate, $\checkmark$ can accurately incorporate.

\begin{tabular}{|c|c|c|c|c|c|c|c|}
\hline Approach & 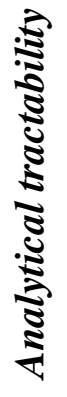 & 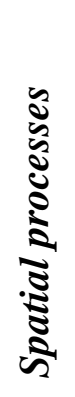 & 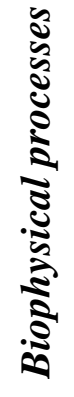 & 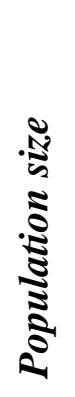 & 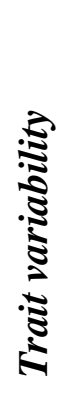 & 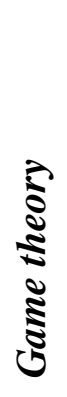 & $\begin{array}{l}\text { Foundational paper } \\
\text { and recent literature } \\
\text { review for each } \\
\text { approach }\end{array}$ \\
\hline Population & $\checkmark$ & $x$ & $\sim$ & $\checkmark$ & $x$ & $x$ & $\begin{array}{c}\text { (Lotka 1924), } \\
\text { (Jeltsch et al. 2008) }\end{array}$ \\
\hline Individual & $x$ & $\checkmark$ & $\checkmark$ & $\checkmark$ & $\checkmark$ & $\checkmark$ & $\begin{array}{l}\text { (Botkin et al. 1972), } \\
\text { (Shugart et al. 2018) }\end{array}$ \\
\hline Continuum & $\checkmark$ & $\checkmark$ & $\sim$ & $x$ & $x$ & $x$ & $\begin{array}{c}\text { (Lefever and Lejeune 1997), } \\
\text { (Meron et al. 2019) }\end{array}$ \\
\hline
\end{tabular}




\section{Figures}

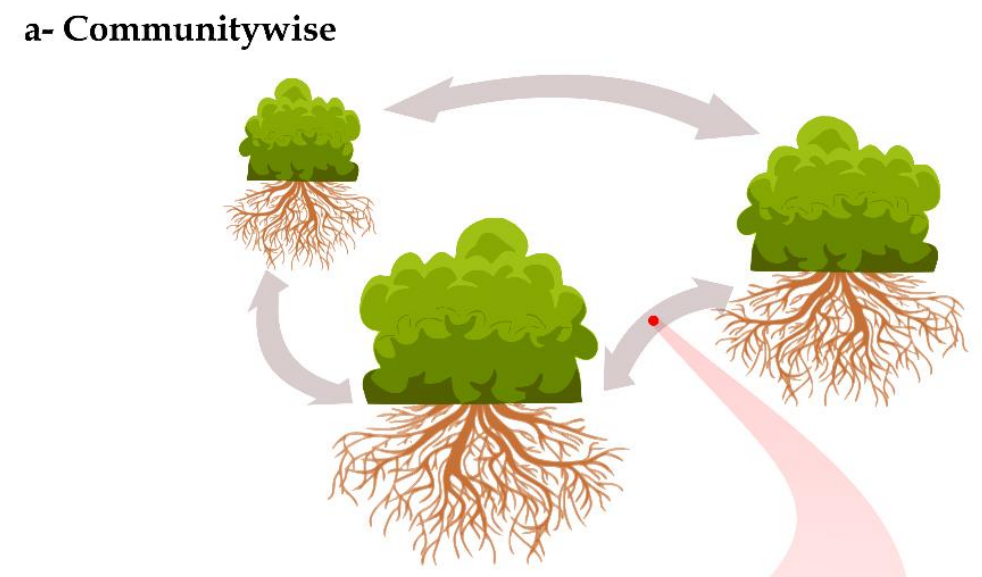

b-Pairwise

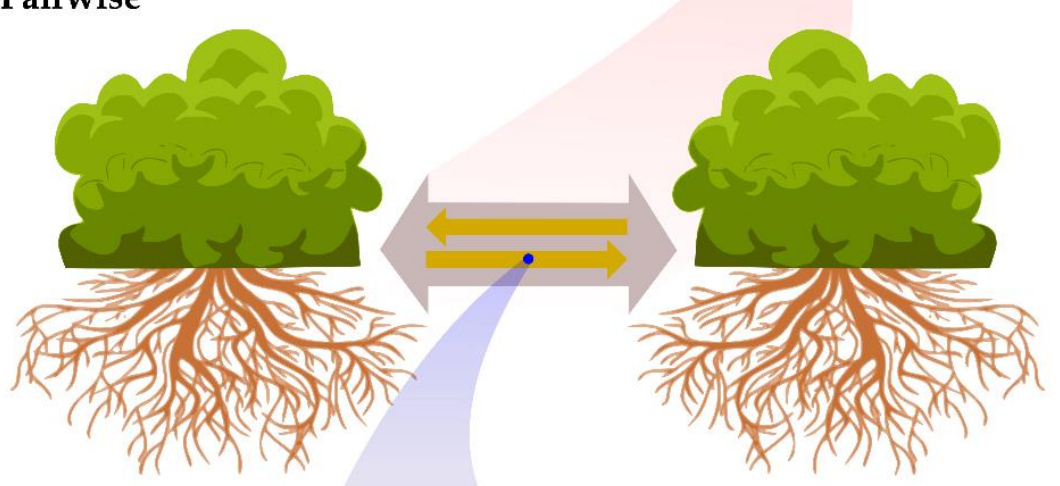

c- Mechanistically

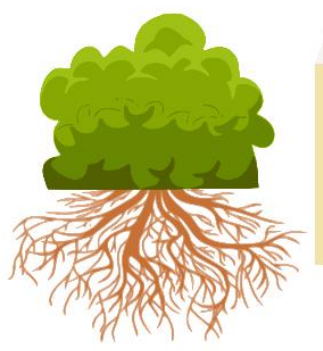

Increase humidity Attract pollinators

Competition for light

Repel hervibores Reduce abrassion Reduce evaporation Increase infiltration

Competition for water

Figure 1: Nested levels of biotic interactions among individuals: a- Communitywise, individuals can be assumed to interact with one another in pairwise interactions. b-Each pairwise interaction is actually composed of two directional net interactions. c- At the mechanistic level, the net interaction is the observable outcome of a diverse set of biophysical mechanisms. 


\section{Primary process Intermediary processes Interaction forces}

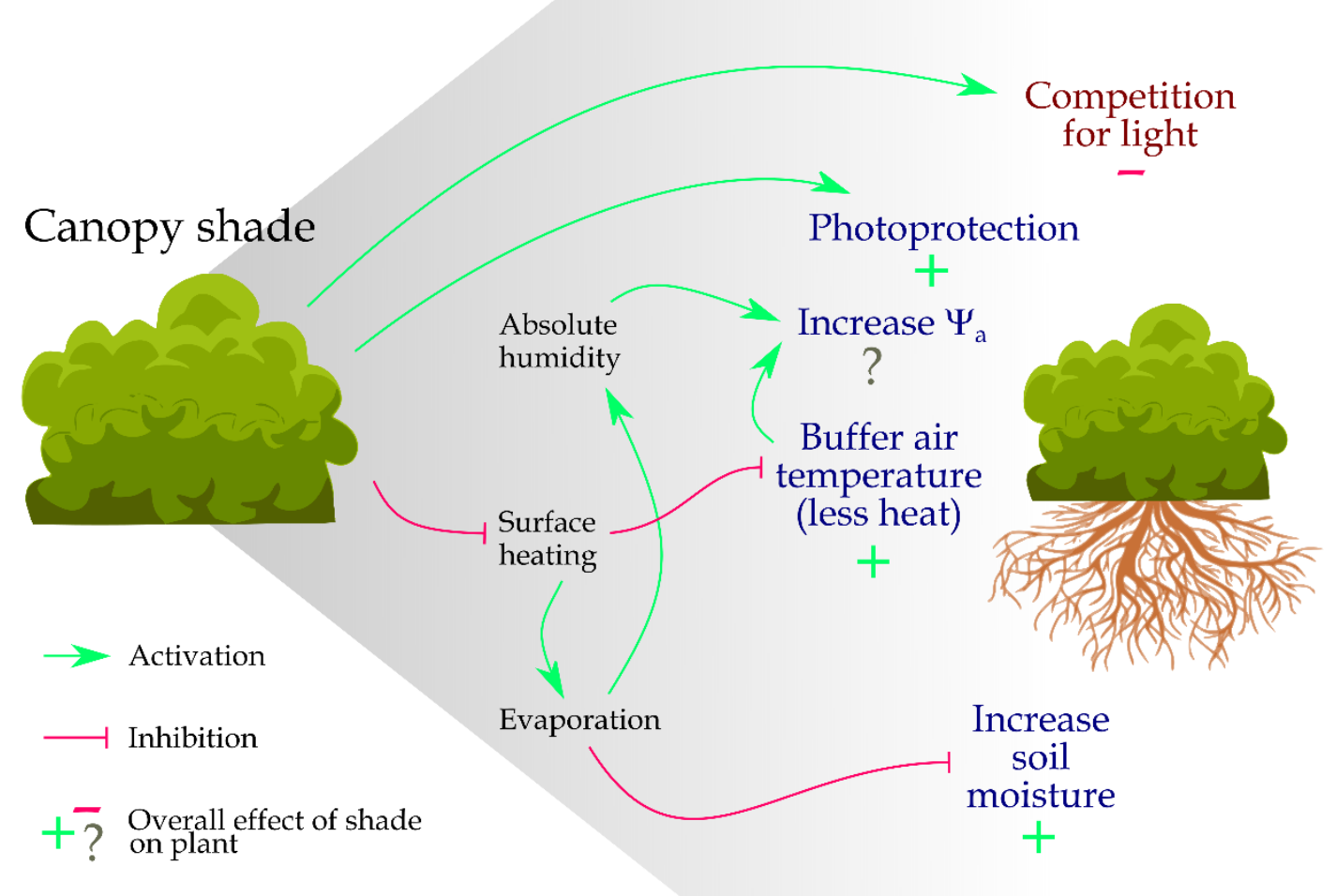

Figure 2: Schematic example of how a primary process, canopy shade, affect interaction forces in hot semi-arid and arid systems. The primary biophysical processes of plant interaction are defined as the direct biophysical modification of the habitat by a plant, ultimately (not directly) affecting the success of other plants growing nearby. 


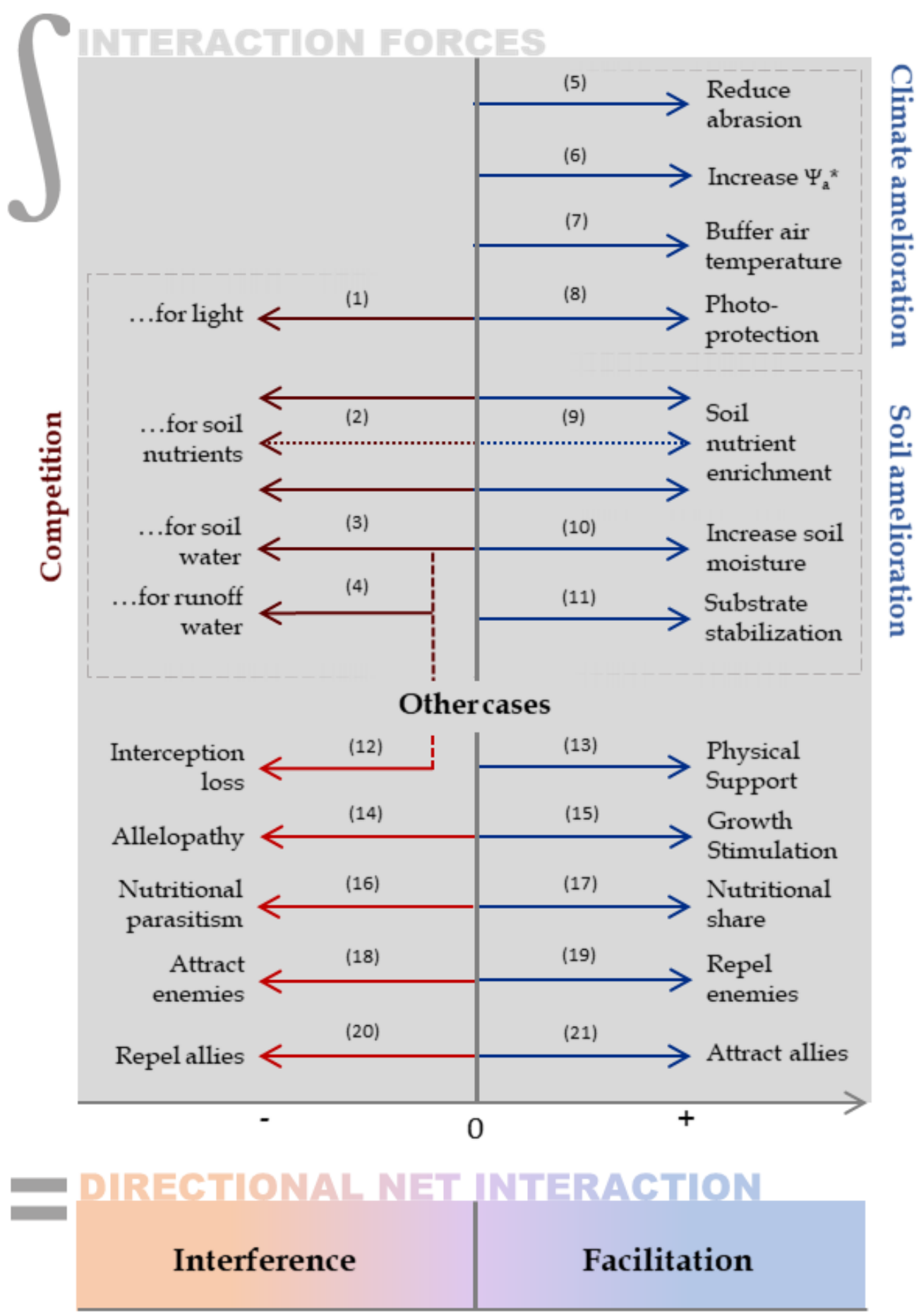

Figure 3: Dissecting net interactions. Mathematical symbols on the left of the boxes are included to indicate that it is the integration of all interaction forces that determines a single directional net interaction value. Several arrows for soil nutrient forces represent the fact that there are different nutrients involved (N, P, K, etc.). Numbers nest to the arrows reference explanation in the text. *Atmospheric water potential. 
Competiton for light a- Individual optimal

c- Collective optimal

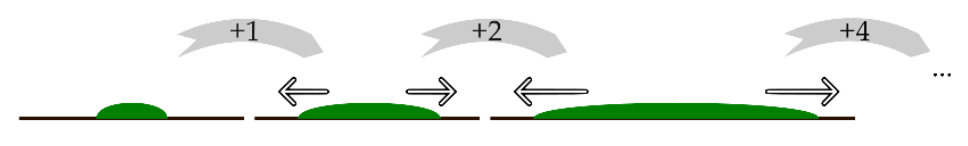

b- Evolutionary Stable Strategy: arms race

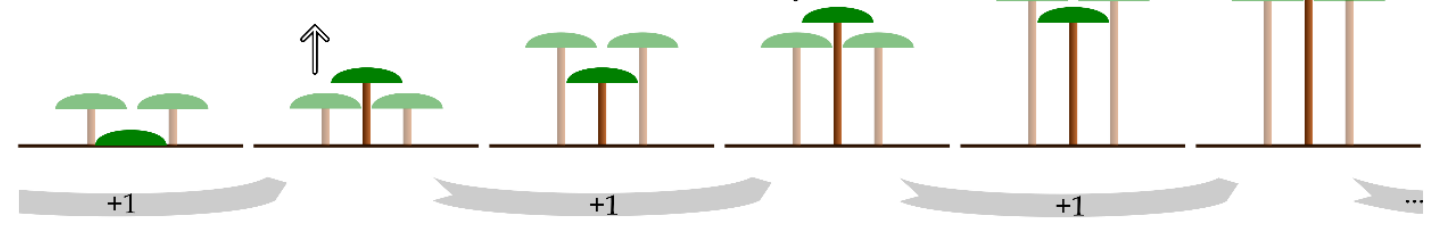

Competition for soil resources

d- Individual optimal

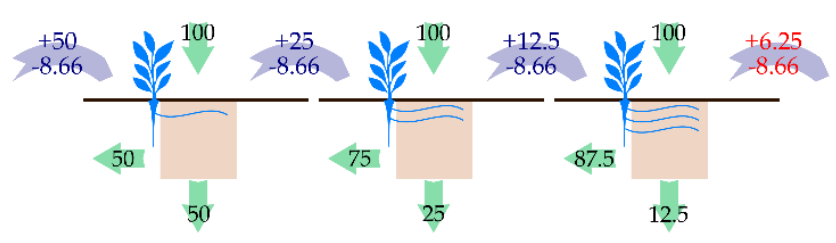

Total $=3$ roots

Net gain $=61.52$ f- Collective optimal

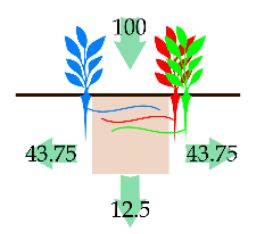

Total $=3$ roots Net gain $=61.52$

e- Evolutionary Stable Strategy: tragedy of the commons

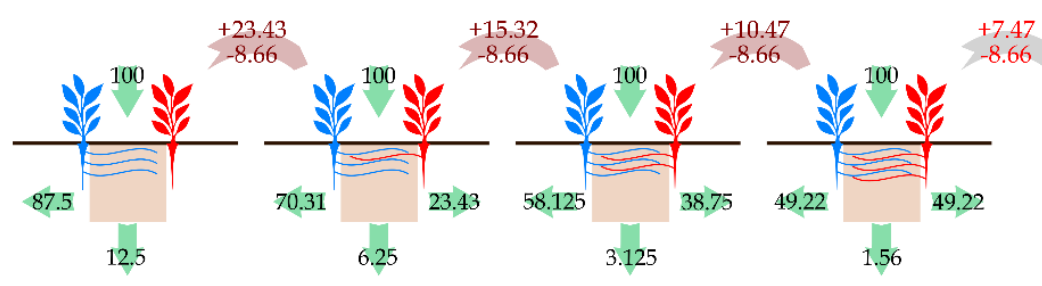

$$
\begin{array}{r}
\text { Total }=6 \text { roots } \\
\text { Net gain }=46.48
\end{array}
$$

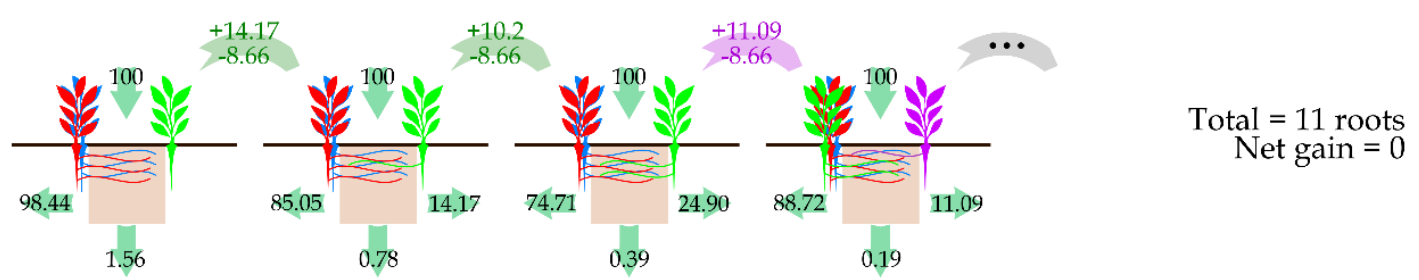

Figure 4: Simplified examples illustrating the tragedy of the commons as a result of evolutionary stable strategies in plant competition for light and soil resources. In competition for light a- a plant with initial crown size 1 intercept 1 unit of sunlight and allocate this energy in growing out, doubling its crown area, hence its solar interception, and investing 2 in growing out in the next time step, and so on. But in the case of $\mathbf{b}$ - an 
ESS, neighbors tend to overgrow the plant getting the benefit of asymmetric competition, hence the focal plant will invest 1 in growing up rather than out, reaching the canopy but not increasing its interception area. This is different from the c-collective optimum in which plant crown are territorial but plants do not invest in trunk either. In competition for soil resources, $\mathbf{d}$ - a plant will decide whether to grow a root in a patch of soil where 100 units of resource are available depending on the marginal gain. In the case in which each root costs 8.66 units of resource, the first root uptakes 50 units, and each extra root increase the uptake by $50 \%$ ( 2 roots uptake 75 units, 3 roots 87.5 , 4 roots 93.75 , and so on) the plant will stop with two roots as the marginal benefit of adding a fourth root is negative $(93.75-87.5-8.66=-2.41)$. One can calculate that $\mathbf{e}-$ the ESS predicts other plants will find a marginal benefit of growing a fourth and more extra roots, as they will be stealing nutrients from other plants' roots. However, $\mathbf{f}-$ the collective optimum is attained, like the individual optimum, when there are no more than 3 roots in the patch, with which the plant community can maximize the net collective gain at a value of 61.52 $(=87.5-3 * 8.66)$ 
1130

$\rightarrow$ Vapor flow

$\leftrightarrow$ Water flow

$\rightarrow$ Water flow inside plant

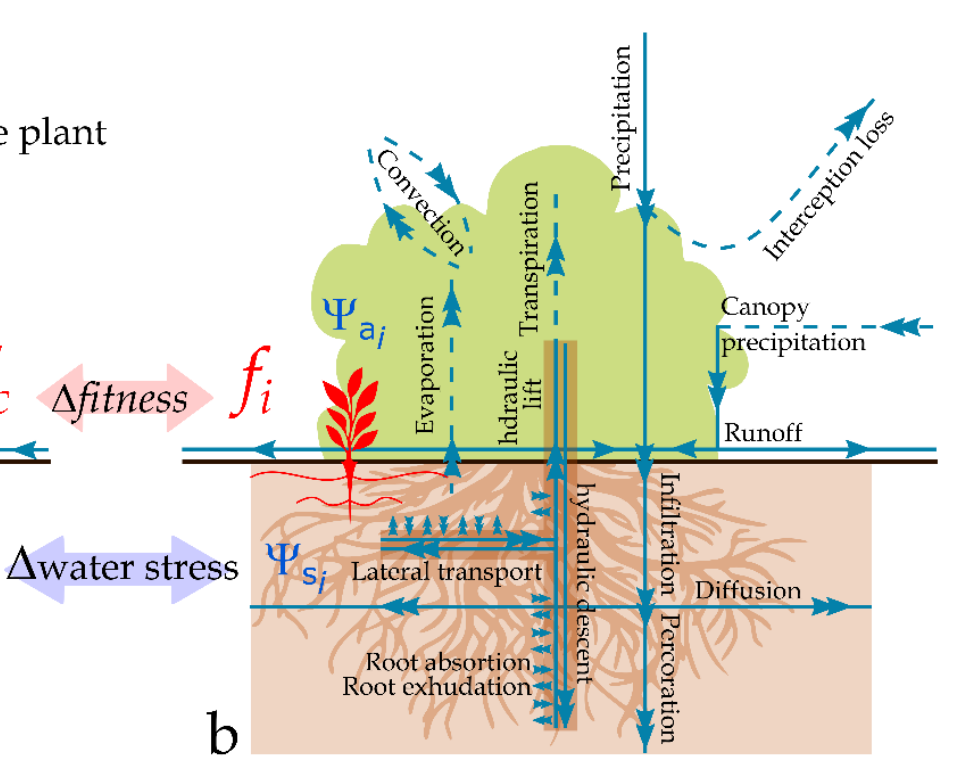

Figure 5: Schematic of two approaches to the net interactions. Phenomenological studies observe the effect of a neighbor (shrubby plant) on a focal plant (red plant), by measuring a fitness surrogate of the focal plant when growing a- alone (control, $f_{c}$ ), or $\mathbf{b}$ - in the presence of that neighbor all else equal (interacting, $f_{i}$ ). Alternatively, an integrative mechanistic study is based in comparing the control and the interacting physical environment of the focal plant. A possible approach to the mechanistic study would be to focus on a resource and consider how the neighbor alters the resource dynamics. In the figure, the resource is water, and modeling water fluxes a- with and b- without the shrubby plant allows to compare the water stress to which the plant is exposed through predictions of soil water potentials $\left(\Psi_{\mathrm{s}}\right)$ and atmospheric water potentials $\left(\Psi_{\mathrm{a}}\right)$. 


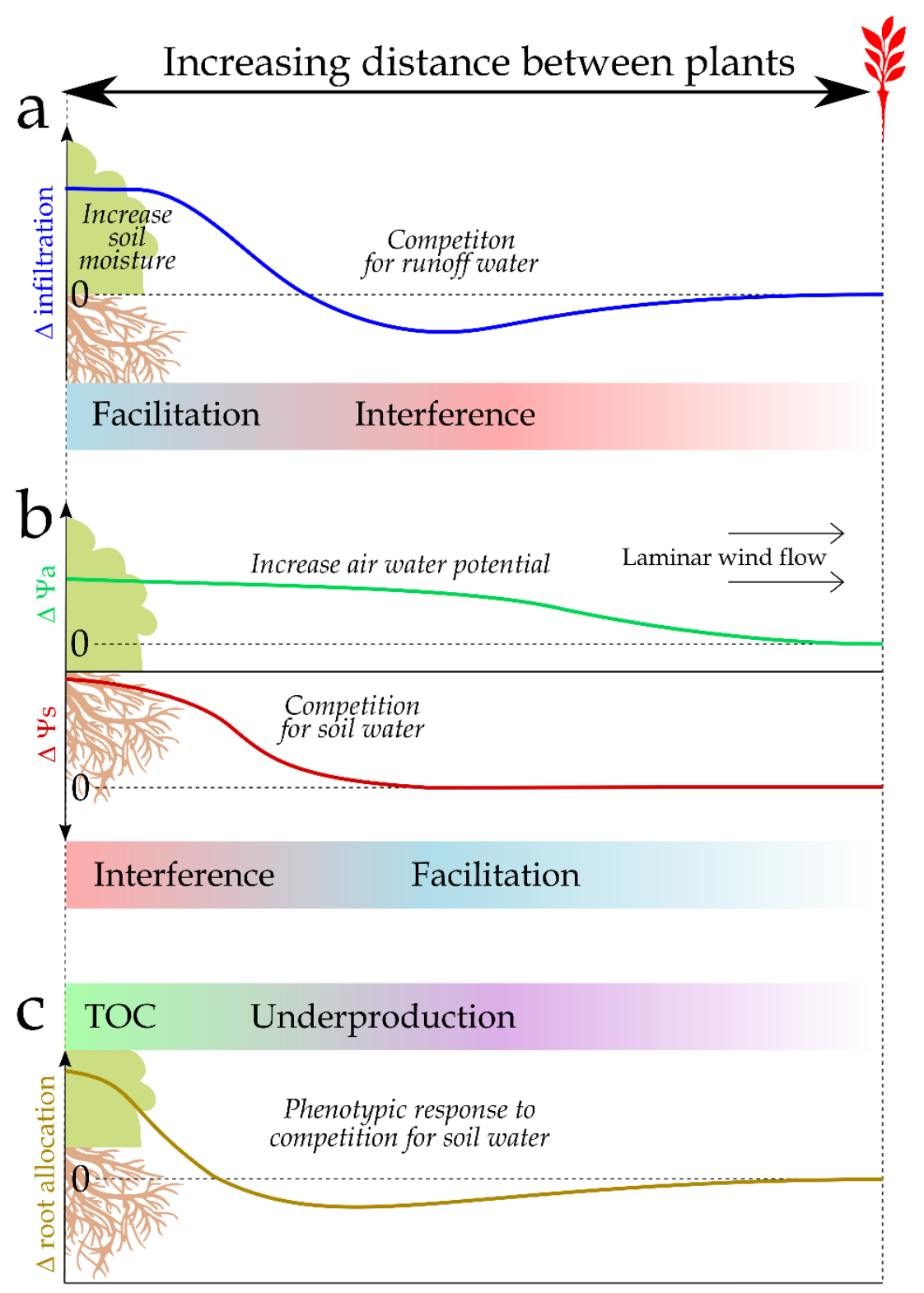

Figure 6: Schematic of how the distance between plants is an important driver of some interaction mechanisms. a- The classic SDF showing how short-range facilitation and long-range interference may emerge by plants altering soil infiltration capacity of soil. b-

1145 An alternative SDF showing how short-range interference and long-range facilitation may emerge from combining the interactions forces of competition for soil water and increase in atmospheric water potential acting at independent spatial scales. c- The spacedependent phenotypic response of plants to competition for soil resources. 


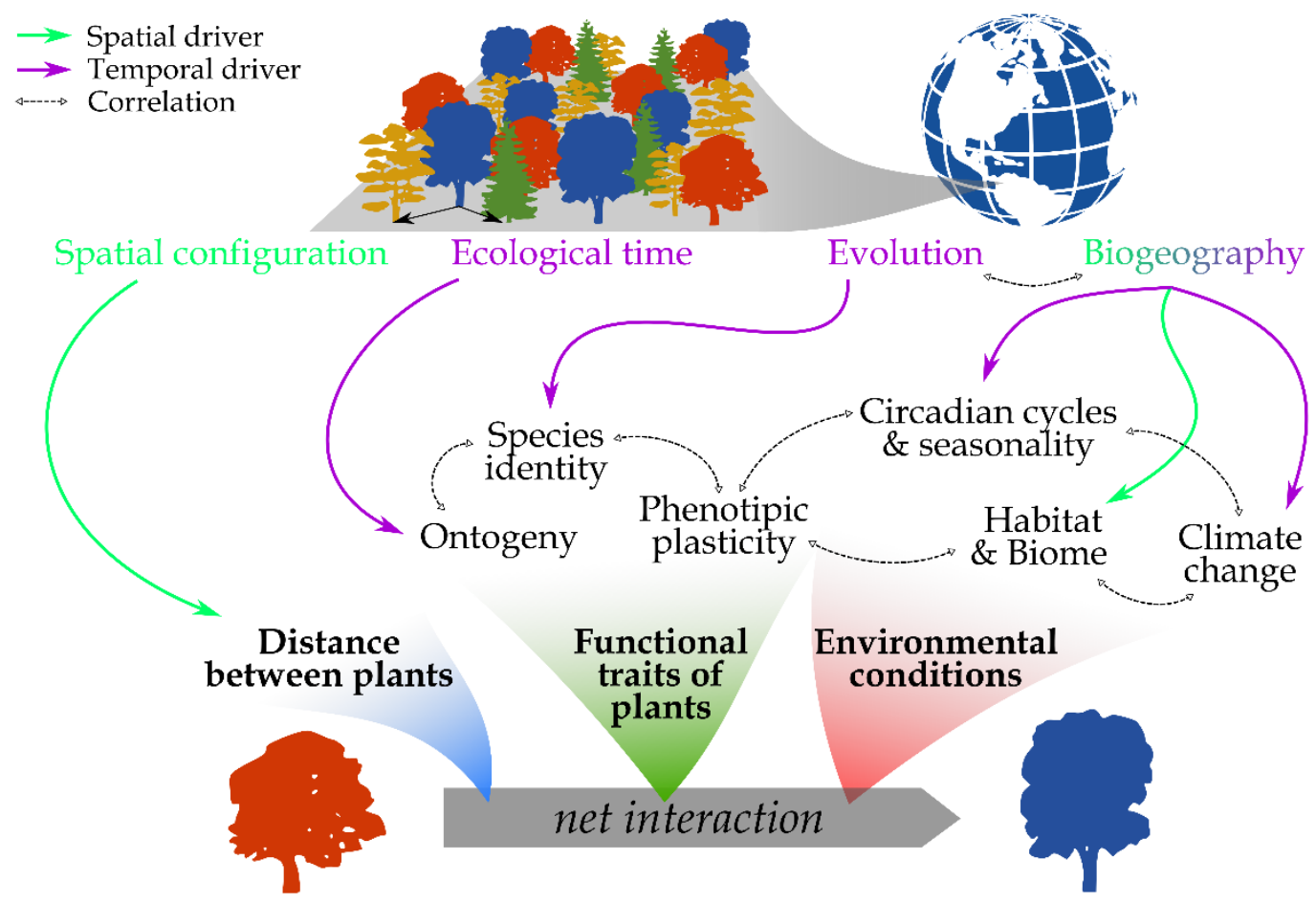

1150 Figure 7: Schematic of the main spatial and temporal drivers of the net interaction, mediated mechanistically by the distance between plants, the functional traits of the two plants, and the environmental conditions in which the interaction takes place. 
a- Biological scales in community ecology

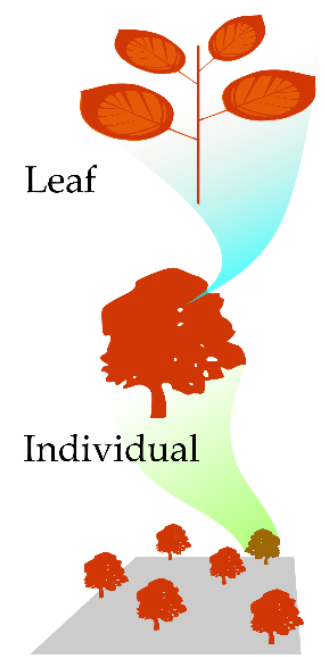

Population
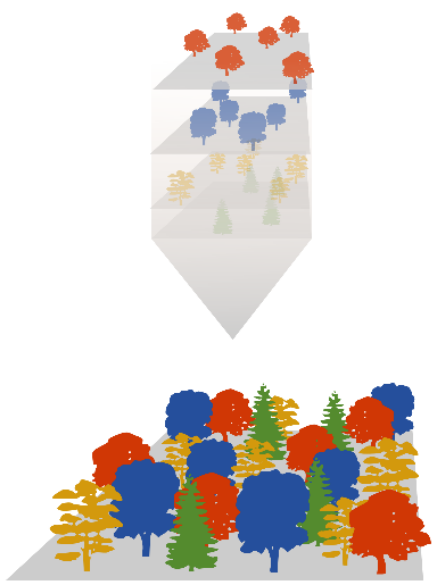

Community b- Interaction approaches

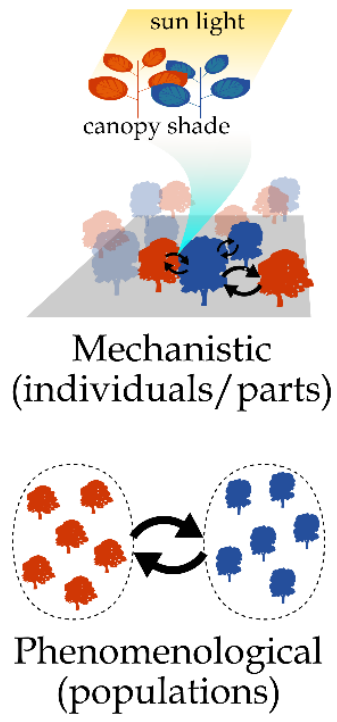

1155 Figure 8: Schematic of a- the different biological scales of plant communities that are of interest for ecologists and $\mathbf{b}$ - some examples of how the biotic interactions among plants can be approached from these different scales. 